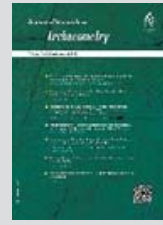

\title{
Investigation and presentation of the geochemical model of silver-based metal objects from the Elamite period (Study samples of silver objects in the collection, Jobji, Kalmakareh, Arjan)
}

\author{
Massoud Darabi* \\ Ph.D. student of Isfahan University of Arts, Isfahan, IRAN
}

Received: 23/05/2021

Accepted: 21/05/2021

\begin{abstract}
During the '60s and '80s, three valuable Elamite collections of Arjan, Kalmakareh, and Jobji were accidentally discovered in the west and southwest region of Iran. The quantity and value of their metal objects indicate the glory of the Elam era in Iran. This paper examines the data obtained from the geochemical study of silver alloys from the mentioned collections. In this paper, 23 silver samples from the collections have been analyzed by portable XRF method to test the alloy and to answer the two major research questions. Investigation of the data revealed that the presence of the Platinum group elements (PGE) Platinum-Group Elements can be classified as a geochemical model of these objects. Also, the presence of the element iridium could be determined as their chemical fingerprint. Based on these findings, it can be said that the primary ore of the objects of these three collections was supplied from a single geographical area.

Keywords: Metal objects based on silver, geochemical, Kalmakareh, Jobji, Arjan, Elamite period
\end{abstract}

\section{Introduction}

The Elamite period has been considered as a political and cultural unit after the period of the Assyrian attacks. Evidence of this claim is the discoveries related to this period in Jobji, Arjan, and Kalmakareh. Jobji and Arjan objects have been discovered by the Cultural Heritage Organization but Kalmakareh objects were found and confiscated by smugglers [1].

This has put the authenticity of the objects in this collection under a shadow of professional speculations to this day. The proposed approach for examining these three sets is the authentication method based on the assessment of alloys, metalworking technology, and fabrication and microstructures. This paper achieves one of the aims of this approach in presenting the data obtained from the geochemical study of the composition of silver objects of the Elamite period derived from the information obtained from the objects of these three regions. Based on this approach, this paper examines the alloy and answers two basic questions related to this area:First of all, will the combination of alloy and of these three regions make it possible to present a geochemical model of Elamite silver from these regions?Secondly, can finding a geochemical model of silver objects discovered from the Elamite period help to classify the data and identify the chemical fingerprints of these objects?

*Corresponding Author: mm_darabi@yahooo.com

Copyright $(2021$, the Authors / This open-access article is published under the terms of the Creative Commons Attribution-NonCommercial 4.0 International License which permits Share (copy and redistribute the material in any medium or format) and Adapt (remix, transform, and build upon the material) under the Attribution-NonCommercial .terms 


\title{
Material and method \\ Case study
}

The Elamite tomb of Arjan was discovered $250 \mathrm{~km}$ Southeast of Shush. According to reports, there are only two silver objects, a silver straw, and a vase, in the Arjan collection. Kalmakareh Cave is located $13 \mathrm{~km}$ Northwest of Poldakhtar city of Lorestan [27] Findings of pottery and other cultural materials on the surface of cave halls confirm the existence of the New Elamite period in the 6th century BC [29-30]. Nazaratizadeh has studied all the objects of the Kalmakareh treasure located in the Fala-Ol-Aflak castle, and a number of objects of this treasure in the National Museum. According to her studies, the objects of this treasure can be classified into the categories of bowls, animal rhytons, trays, vases, and jewelry [34]. Elamite, Achaemenid, and Parthian pottery have been observed on the surface of the Jobji site discovered in 2007. Of the hundreds of objects discovered in this valuable treasure, 29 were silver objects (Fig 3). From these three collections, a total of 23 objects were provided for analysis by this project, which is presented in Table 1 of the information of these objects.

\begin{abstract}
Method
Analytical approaches with the aim of quantifying chemical elements are the first and probably most practical applications of XRF analysis in the study of metal artifacts [36] [37] [40]. Because the objects were mostly intact and it was impossible to sample the objects, it was decided to use the portable XRF method for analysis. Since portable XRF provides spot-based elemental analysis, and the chemical composition of ancient and historical artifacts is heterogeneous, this type of analysis must be taken from several spots and then obtain an average from the results. In this study, the analysis was performed at three points of each sample and the presented results are the final average. Samples were tested in this method in a completely non-destructive manner without carbon or gold coating. The conditions for performing XRF fluorescence spectroscopy test are manual X-ray of Niton XL3tGOLDD + 950 model from Thermo Scientific Company and the results are semi-quantitative-semi-qualitative.
\end{abstract}

\section{Results}

Out of 23 analyzed objects, 13 objects belong to the Jobji collection, 9 objects belong to Kalmakareh and 1 object belongs to the Arjan collection. The analysis results of each group of samples are presented in Tables 2, 3, and 4.

\section{Discussion}

Of the 13 objects analyzed from Jobji all, except for one sample with a value of $88.72 \%$, contain from $93.04 \%$ to $97.3 \%$ silver. The amount of gold in these samples ranges from $0.334 \%$ to $1.75 \%$. It seems that the gold in the samples has originated from ore. And we also suspect that the three samples with the gold make up of $1.16 \%, 1.45 \%$, and $1.75 \%$ suggest the possibility of added gold to the alloy, or that silver has been extracted from cerussite [19-54-59]. In these samples, the amount of copper varies from $0.35 \%$ to $8.71 \%$. It could be possible that the addition of copper was intentional and was used to make an alloy. Lead (Pb) is visible in all samples with a frequency of $0.036 \%$ to $1.59 \%$. Iridium (Ir) was observed in 12 samples with a frequency of $0.09 \%$ to $0.793 \%$. Palladium (Pd) was also present in 9 of the studied samples from $0.011 \%$ to $0.023 \%$.

From the analysis of 9 objects of Kalmakareh, except for one sample, there is silver from $93.18 \%$ to $97.66 \%$. The amount of gold in these samples is from $0.373 \%$ to $0.573 \%$. The amount of copper varies from $1.37 \%$ to $9.66 \%$. Lead $(\mathrm{Pb})$ is visible in all samples with a frequency of $0.197 \%$ to $0.281 \%$. Among the 9 samples studied, all 9 samples contained iridium (Ir) with a frequency of $0.011 \%$ to $0.183 \%$. Palladium (Pd) was also present in 2 of the studied samples from $0.014 \%$ to $0.024 \%$.

In the analysis of the Arjan vase, there is $96.64 \%$ silver and $0.378 \%$ gold. The amount of copper in this object is $1.51 \%$ and it suggests that it was not as much copper used for the production of alloy and is actually one of the impurities of the original metal. In this object, some elements of the platinum group such as $\mathrm{Pd}$ with $0.03 \%$, Rh with $0.011 \%$, and $\mathrm{Ir}$ with $0.34 \%$ are visible. In this 
work, the traces of platinum group elements can be seen in its geochemical model.

This amount of lead, in the studied samples, is the remains of the molding process. Indium and cadmium usually come from lead ore deposits and can be a clue to the connection of objects in this collection with other objects in this period.

\section{Conclusion}

Examining the results of object analysis of these three regions leads us to examine and focus on the amount of platinum group elements in these collections. Metals of platinum group elements include 6 metallic elements $(\mathrm{Pt}),(\mathrm{Pd}),(\mathrm{Ru}),(\mathrm{Rh}),(\mathrm{Ir})$, and $(\mathrm{Os})$ and they are all intermediate metals.

Considering the above data will be helpful in reaching the answers to the two questions raised in this article. In response to the first question: Based on the obtained data, it seems that the presence of Platinum group trace elements as a geochemical model can be expectable for silver objects of the Neo-Elamite period in these three collections of Iran.In fact, the presence of the rare elements in all three categories of objects studied confirms the fact, that the origin and geographical area of the ore of the three groups of objects can be the same.

In answer to the second question, it can be said that since the element iridium is a rare element that is not normally dispersed in all mineral samples and is present in all 23 objects analyzed from all collections, the presence of this element in silver samples from The Elamite period in these three collections can be introduced as the chemical fingerprint of these objects. 


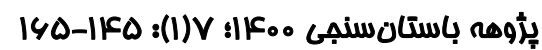

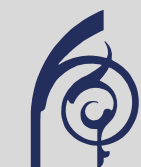

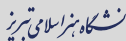

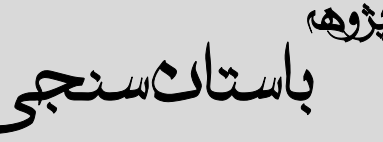

URL: http://jra-tabriziau.ir/

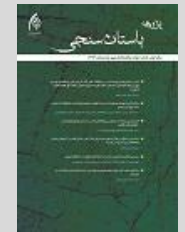

دقالم بِروهشى

بر برسى و ار ائهُ مدل زئوشيمايى اشياء فلزى بر يايئ نقره از

دورة عيلام

(نمونهُ مطالعاتى اشياء نقرهاى مجموعه، جوبجى، كلماكره، ارجان)

مسعود دارابى ا"

1. دانشجوى دكترى حفاظت و مرمت، دانشخاه هنر اصفهان، اصفهان، ايران

در طول دهdهاى •ع تا •1 شمسى سه مجموعه ارزشمند عيلامي ارجان، كلماكره و جوبجى در غرب و جنوب غرب ايران

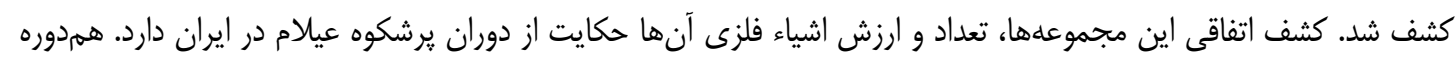

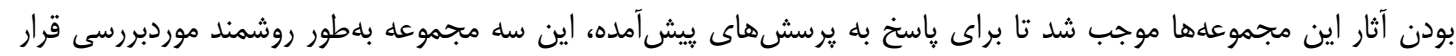

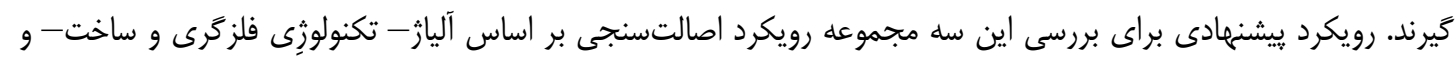

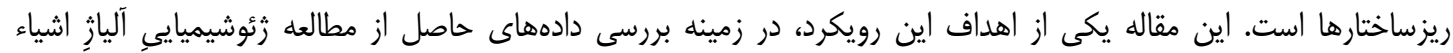

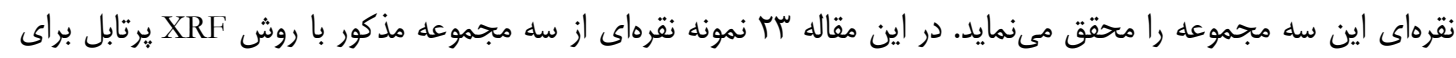

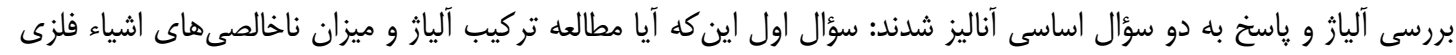

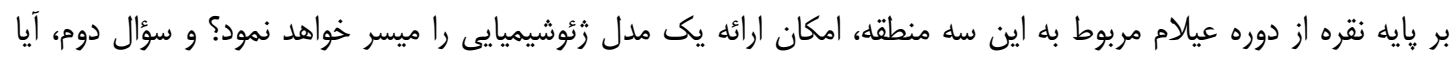

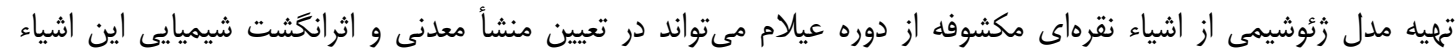

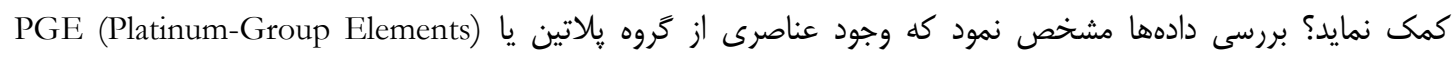
مىتواند بهعنوان مدل زنوشيميايى اين اشياء و وجود عنصر ايريديم به عنوان اثر انخشت شيميايى آنها معرفى گرددد. بر بر اساس

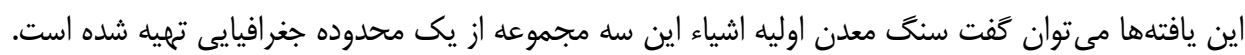

وازَّان كليدى: اشياء فلزى بر يائُ نقره، زئوشيميايى، كلماكره، جوبجى، ارجان، دوره عيلام

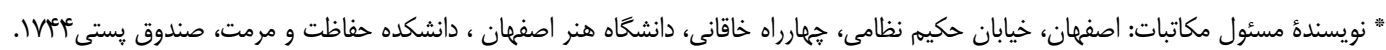

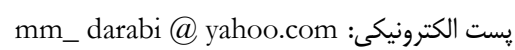
(C) حق نشر متعلق به نويسنده(كان) است و نويسنده تحت مجوز Creative Commons Attribution License به مجله اجازه مىدهد مقاله خاب شده

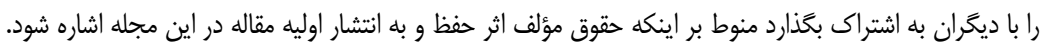


تكنولوزيكى ازسوى ديكر، نيـاز بـه اتخــاذ رويكـردى

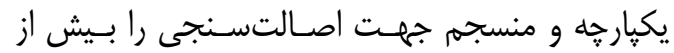

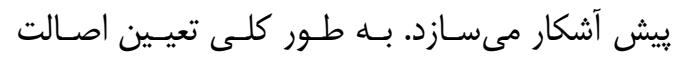

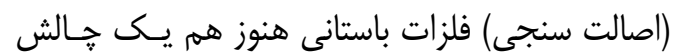

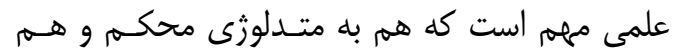
معيارهاى مربوط نيازمند است [4]. رويكرد بيشنهادى

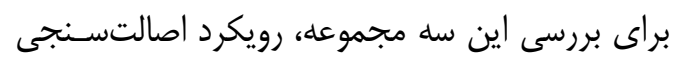

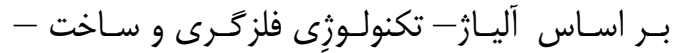

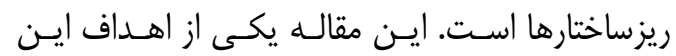

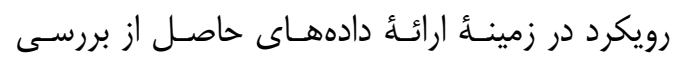

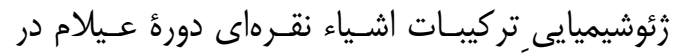

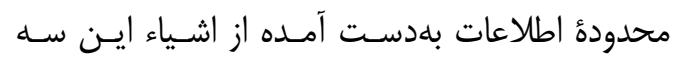

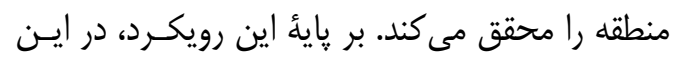

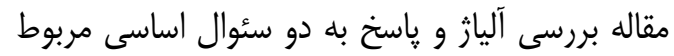

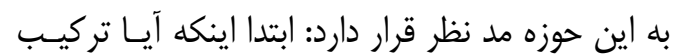

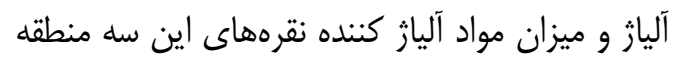

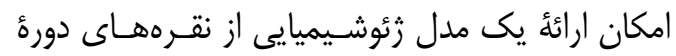

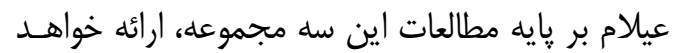
كرد ؟ و دوم اين كه آيا تهيئ مدل زئوشيمى از الشهياء

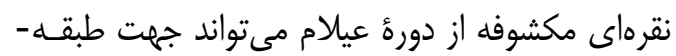

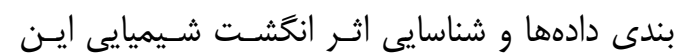
اشياء كمى كند ؟ ادما و وازئ زئوشيمى براى اولين بـار توسط يـك دانشـمند

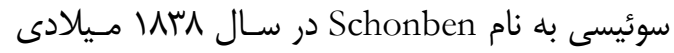

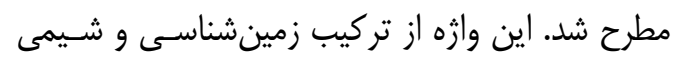

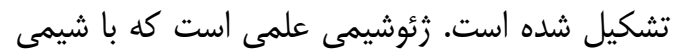

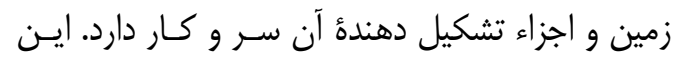

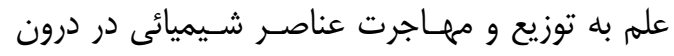

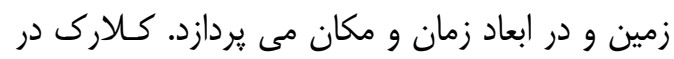
كتـاب داده هــاى زئوشـيمى ( The Data Of (Geochemistry يك سيستم شـيميايى بــه حسـاب آورد كـهـ تغييـرات شيميايى در آن بلوسيلة عوامل مختلف صورت مسى يذيرد. اين هنين تغييرى مستلزم در هم ريختن تعادل

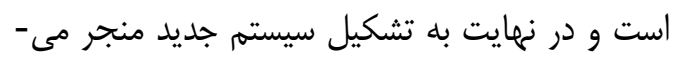

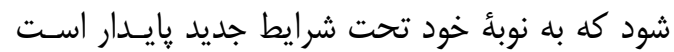

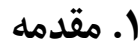

در غرب و جنوب ايران در طول سه دهأ كذشته سـهـ

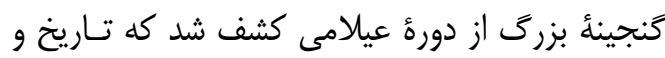

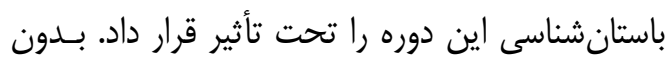

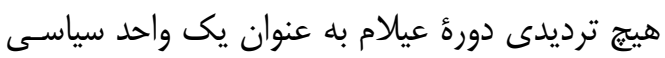

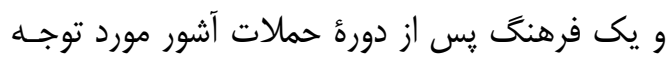

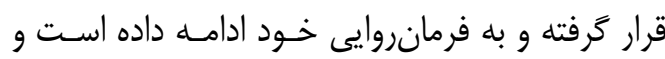

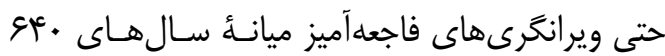

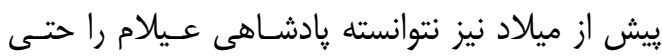

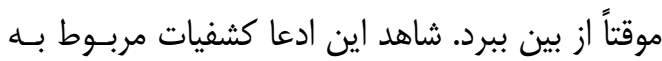

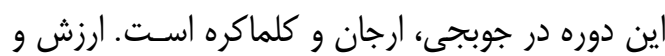

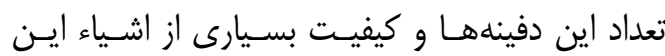

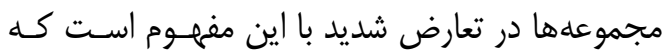

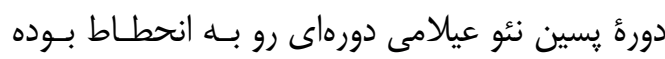

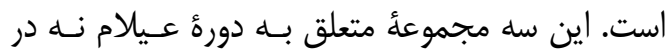

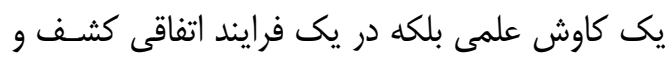

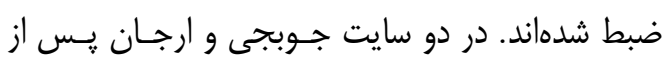

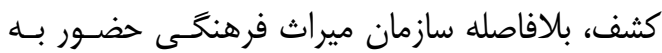

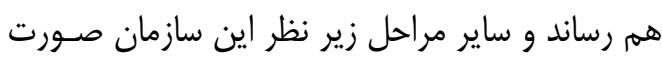

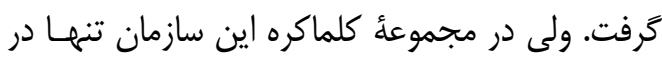
ضبط اشياء از دست متهمين حضور داشته و باسـتانشناسان وِ از دو فصل كاوش در غار كلماكره هـيـيج

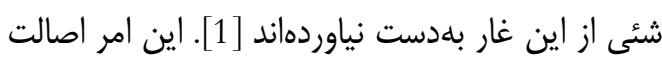

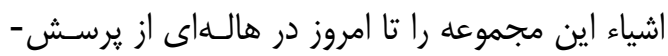

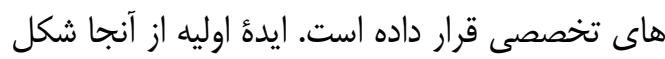

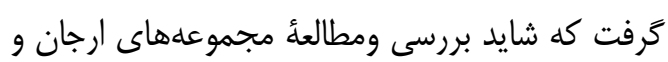

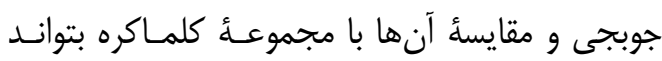
شواهد مستدلى در ردّ يا تعيين اصالت اين اشياء ارائهـ

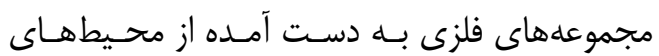

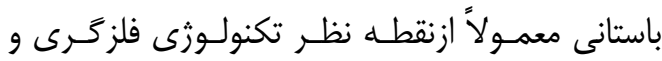

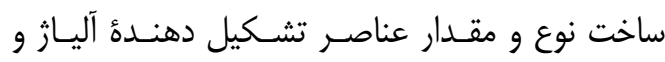
ناخالصـىهـا، تكنيـك سـاخت و خــوردمَى هايشـان

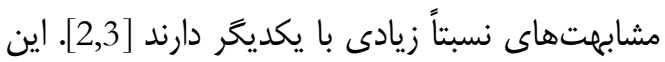

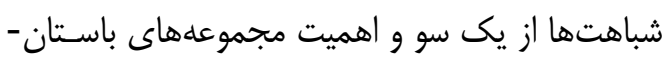

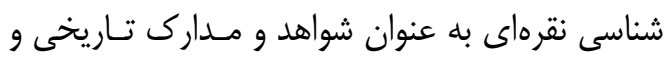


اجتماعى صاحب آنها است، در نظر ترفته مىشـوند

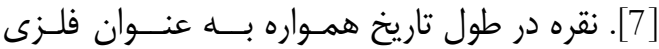

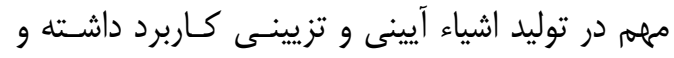

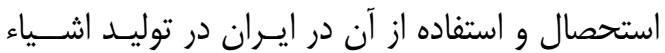

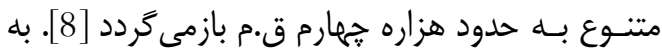

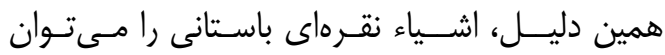
موضوعاتى جالب توجه در مطالعات مختلف در زمينه-

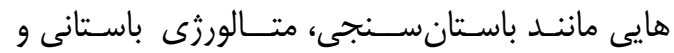

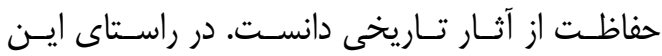
مطالعات اصالتسنجى اشياء نقرهاى جايخـاه ويـزماى

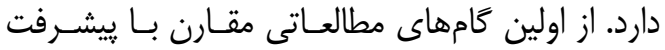

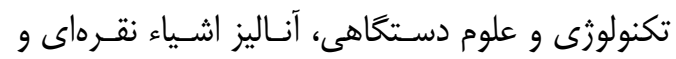

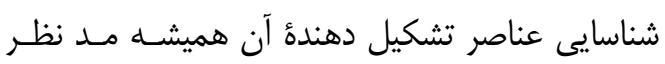
بودهاست [9,10,11,12,13]. با توجه به ترخـأه توليـد

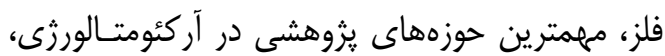

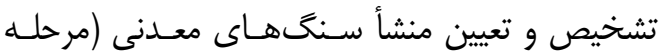

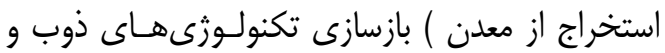

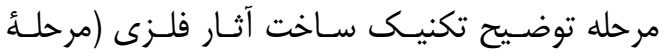

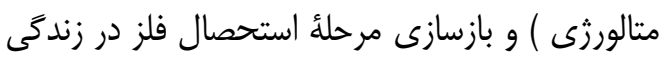

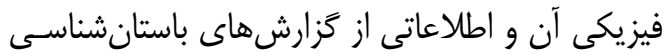

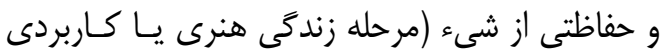

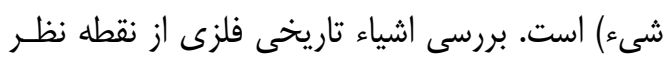

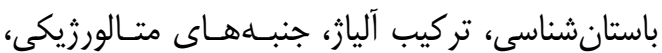

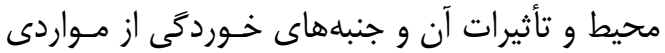
بوده كه در طول قرن كذشته مورد توجه متخصصـان علوم مختلف بوده است. روش استحصال از معادن نقره در قديم با معادن

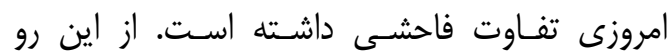

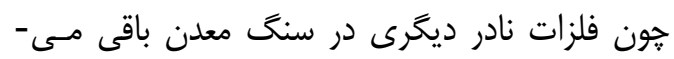

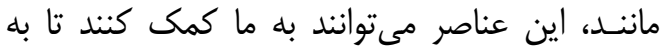

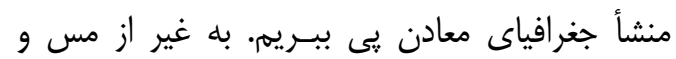
آليازهاى مس، هيج تلاش جدى جنى براى تعيين منشأ نقره با تجزيه و تحليل عناصر كمياب انجام نشده

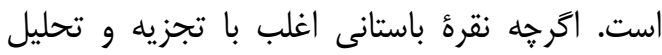
فعالسازى نوترونى (NAA) مورد تجزيه و و تحليل

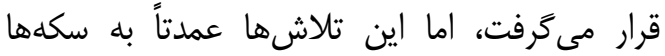

[5]. در حقيقت قلمـرو علـم زئوشـيمى مطالعـأ ايـن تغييرات در داخل يك سيسته زئوشيميائى است. علـم

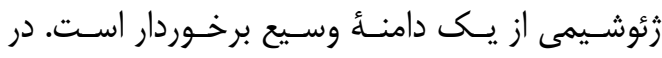

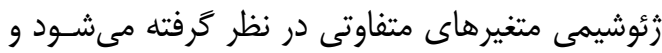

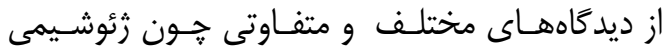

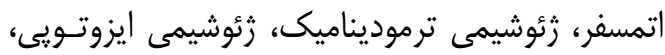
زئوشيمى دريا، زئوشيمى عناصر كميـاب و زئوشيمى تريمى خاكى مى توان به اين علم نغاه كرد. رويكرد ما در اين

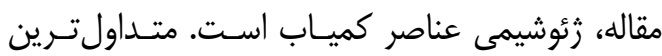
روشهاى تجزيهاى كه در زئوشيمى كاربرد دارد را به به XRF , INAA , ICPMS ,ICP, اختصار مسىتـوان نام برد اما عوامل متعددى در انتخـاب

$$
\text { روش دخيل هستند [6]. }
$$

هر קند ارزش هنرى - تـاريخى - علمس و اقتصـادى

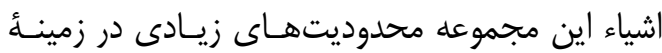

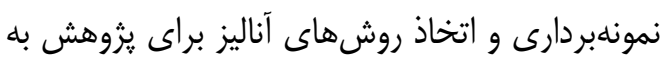

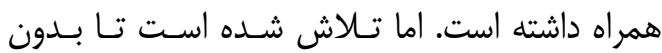

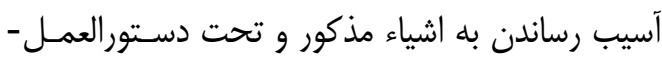

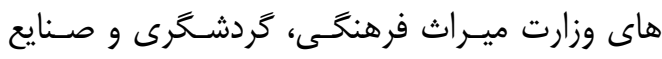
دستى كشور، آزمايشها و مطالعـات بــر روى نماثل نمونسهـ هايى از اين مجموعهها كه در اختيار اين يـروزه قـرار

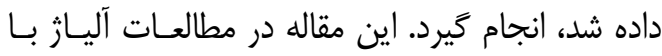

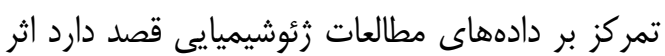
انخشت اشياء فلزى بر ويائُ نقره از دو مجموعئ اصـيل

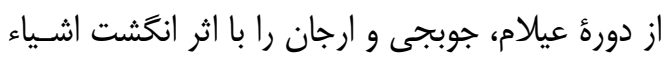
فلزى مجموعأ كلماكره به عنوان سه مجموعأه متعلق آنقان

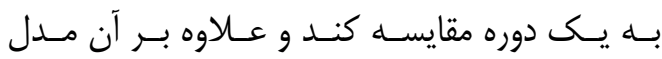

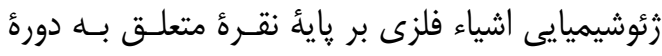
عيلام مربوط به اين سه منطقه را نيز ارائه كند.

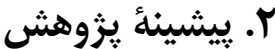

نقره و طلا به عنوان فلزات بـومى در طبيعـت وجـود ئنس

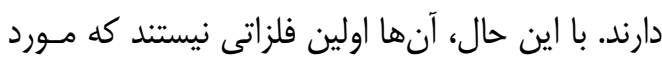

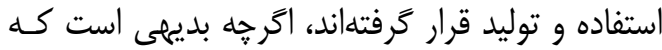
از ابتداى استفاده بسيار مورد استقبال قرار كرفتتهانـد و معمولاً به عنوان اقلام معتبر كه نشان دهنده وضعيت إنيت 
تجزيه و تحليل عناصر كمياب نقره باسـتان بـا روش

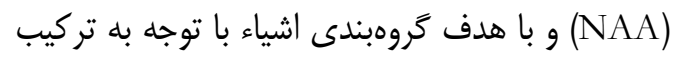

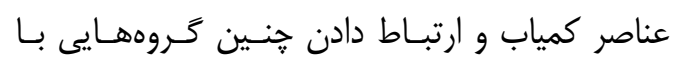
اطلاعات تاريخ هنرى انجام شد. تلاش بــراى تعيـين

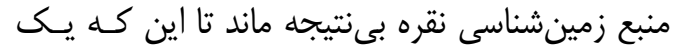

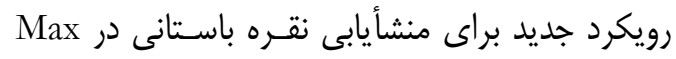
PlanckInstitut für Kernphysik معرفى شد. هالدلبرى جايى اسـت كـه بررسى دهــاى

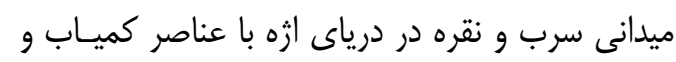

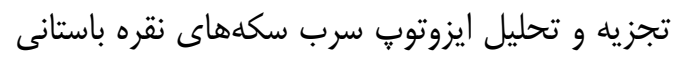
ادغام شد [7]. آنجه مسلهم است اين است كه مطالعـأه

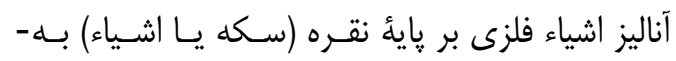
خصوص در قالب تروه و دستههاى تعريف شده، بستر

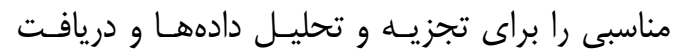
اطلاعات در زمينهاى فوق الذكر، فراهم خواهد آورد.

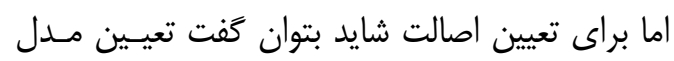

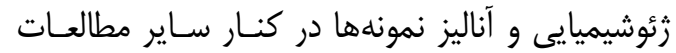

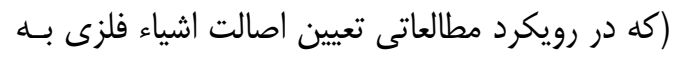

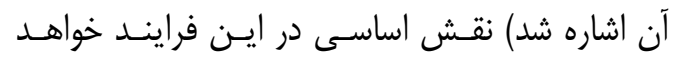

\section{". معرفى محوطهها} س - (. محوطه باستانى ارجان

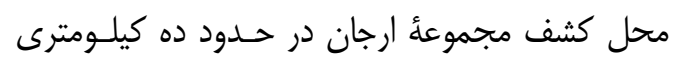

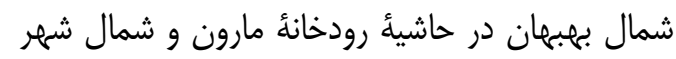
قديم ارجان واقع شده اسـت. ايـن محـل در شهمريور

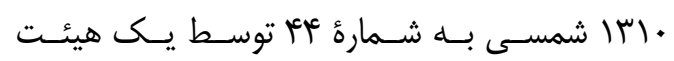

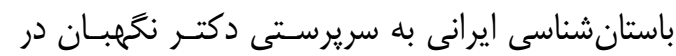

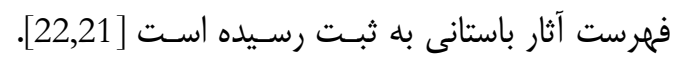

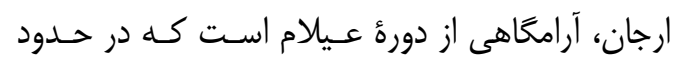
.

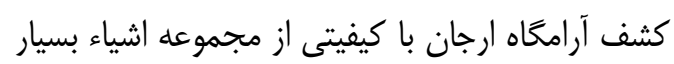

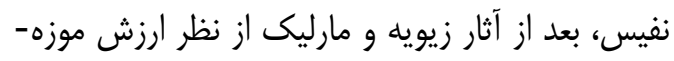

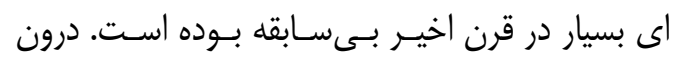

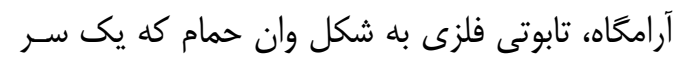

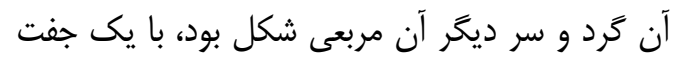

محدود مىشد (به عنوان مثال [11]) و اغلب به دنبال

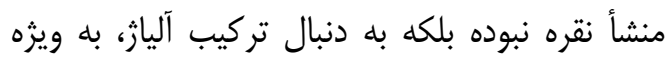
ميزان نقره بوده است [7].

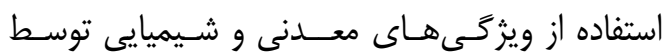
كردوس بـر روى فلـز نقــرهٔ عصــر ساســانى انجــــام شــ [11]. ســـس كونتوس بر روى سكّهـهـاى جهــار

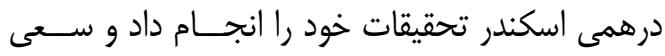

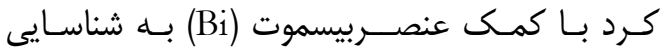

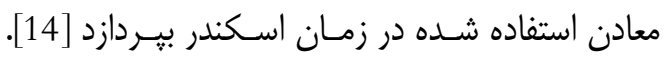

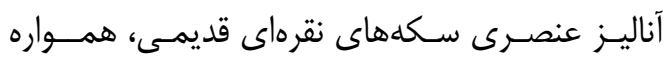

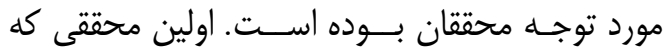

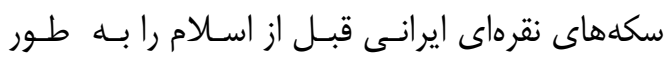

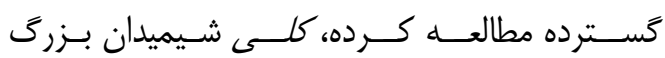
آمريكايى است كه سكّههاى ارد دوم را مورد مطالعـهـ

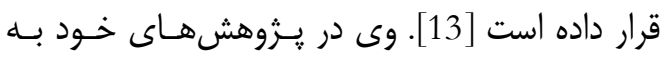

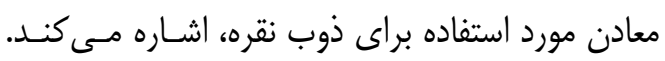

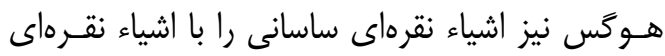

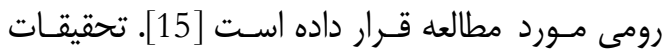

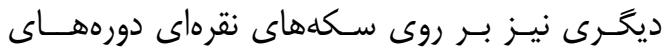
مختلـف ساسـانى، اشـكانى و ايلخانى صورت كرفتــهـ

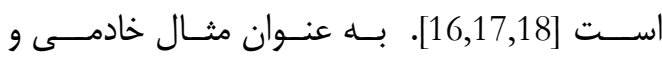

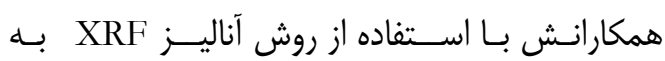

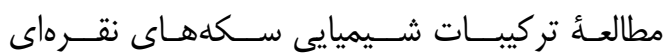

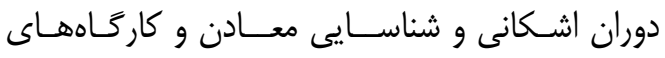

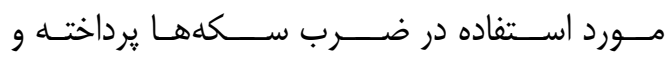

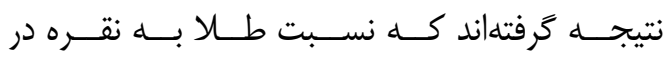

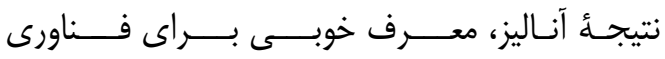

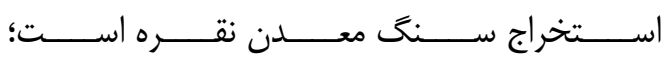

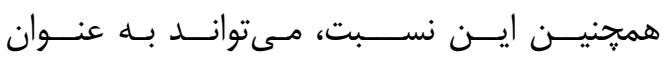

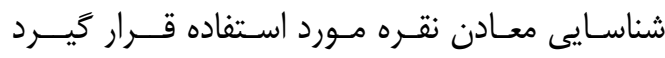

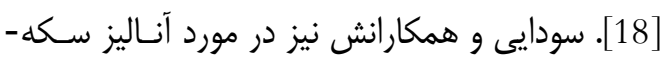

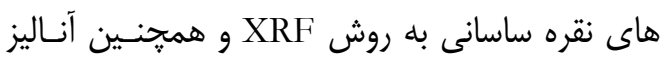

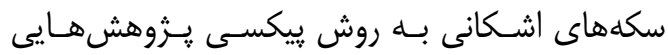

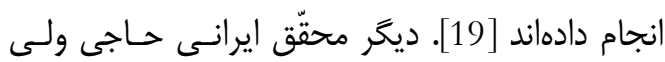
است كه با دستخاه PIXE سكّههاى نقرهاى ساسانى دانى دانى

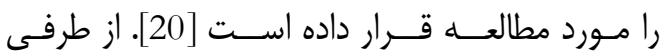


ارجان و آرامخاه خشتى شمر شاهى r بـا لايسـ هفـت شوش هم زمان و مربوط به دورة عيلام نو مرحلـه س

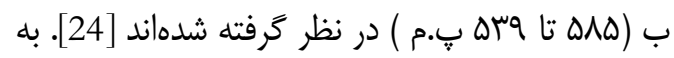

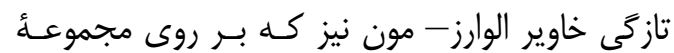

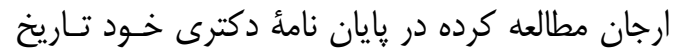

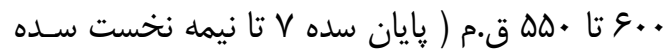

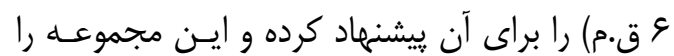
فرصتى مغتنم براى ارزيابى نظريههاى ييشين دربـاره

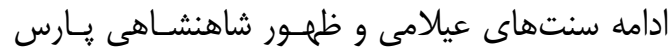
دانسته است [26].

\section{1-1-" اشياء نقرهاى ارجان}

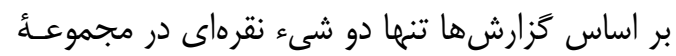

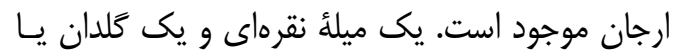

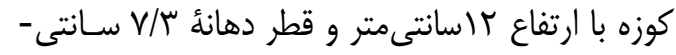
متر كه از خارج تابوت كشف شده اسـت. كاوشـحَران ارجان ميلة سيمين رانى نوش معرفى كردهاند و كويـا مورى نيز هنين ييشنهادى داده است. اين ميله يا لوله

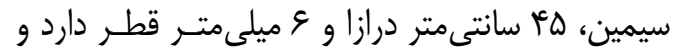
سر آن مخروطى است و به علـت شكستـتى، آشـكار نيست كه باز يا بسته بوده است، اما سوراخهاى ريزى

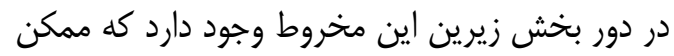

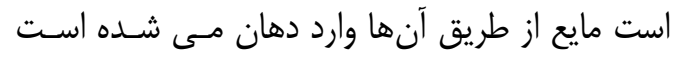

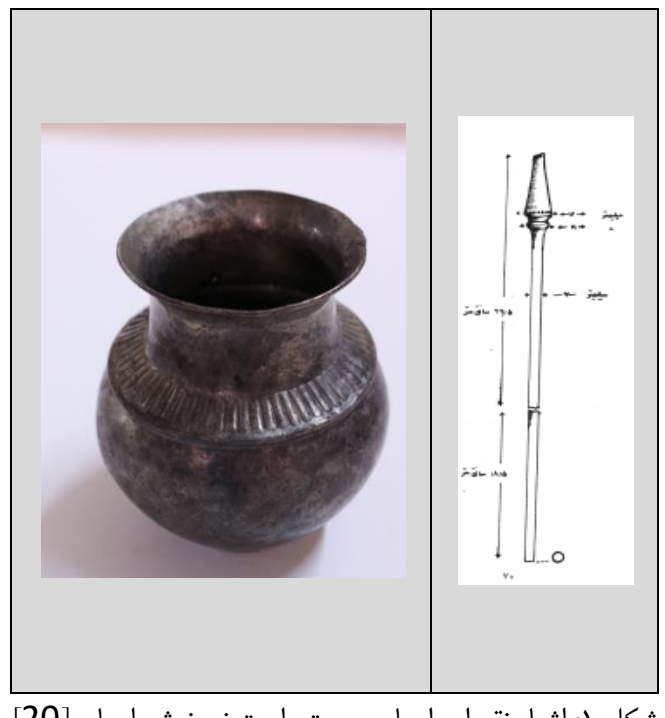

شكل (: اشياء نقرهاى ارجان. سمت راست نى نوش ارجان [20] Fig. 1: Arjan silver objects. Right: Arjan straw [20]

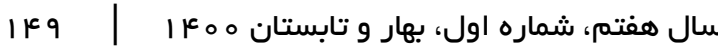

دستخيره در انتهاى هر سـمت، وجـود داشـت. اشـياء مكشوفة تدفينى مفرغى، سيمين و زرين در بيـرون و ورات

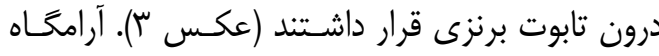
ارجان فضايى به شكل مكعب مستطيل به طـول سرك

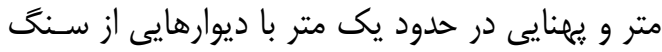

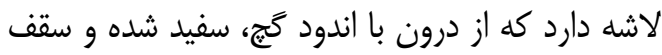

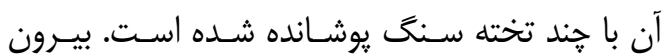

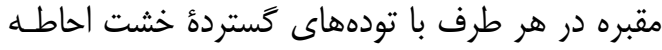

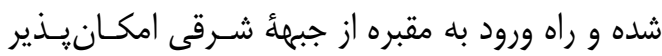

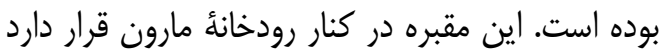
[22]. بر اساس كزارش توحيدى در اين محوطه حلقئ

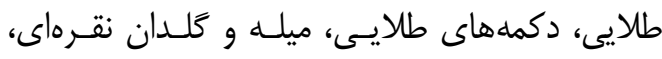

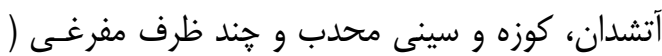
ظرف قيفى شكل با كف مسطح، ظرف به شكل ليوان

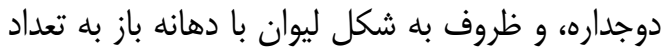

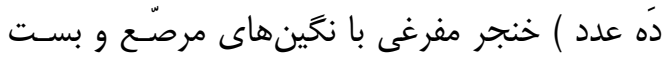

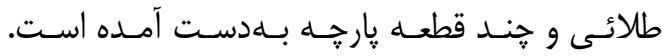

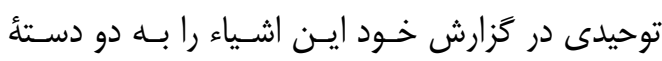

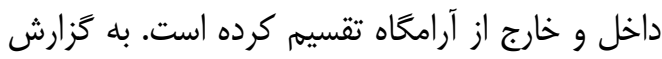
وى حلقع طلايى، خنجر و دكمههاى طلائى در داخل رانل

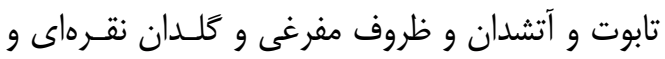

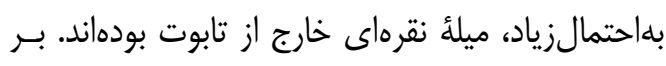

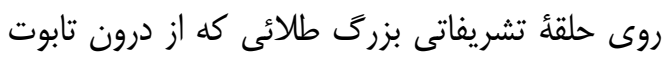
به دست آمده، كتيبهاى با مضمون " كيدين - هوتران يسر كورلوش" نوشته شده بود. اكنون عموم محققان

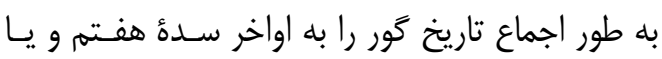
اوايل سده ششم ق.م (يعنى معاصر با اشـياء كَنجينـه

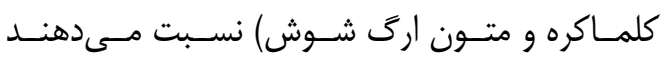
آرامخاه ارجان در آغاز، با استناد به نام كيتين هـوتران

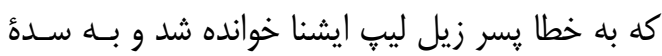

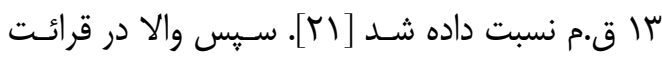

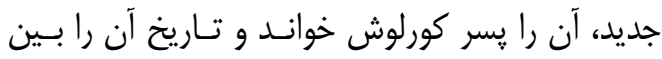

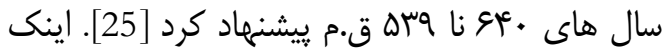

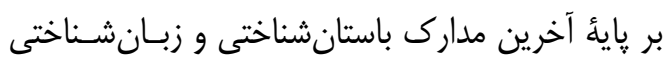

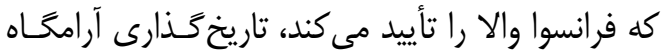




\section{أI-r-r. اشياء نقرهاى كلماكره}

اولين اشياء ضبط شده منسـوب بـهـ كلمـاكره عبـارت بودند از: ماسك طلائى از جهرة انسان (شماره امـوال

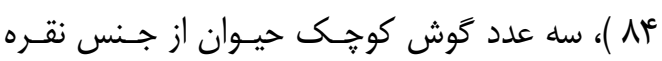

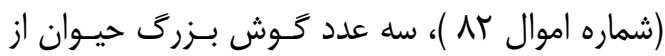

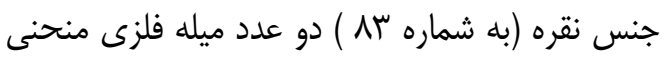

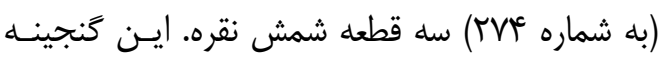

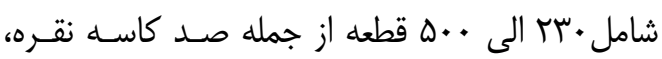

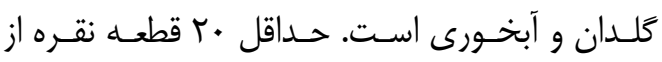

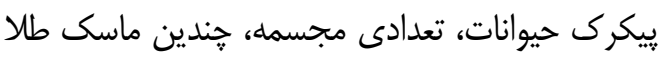

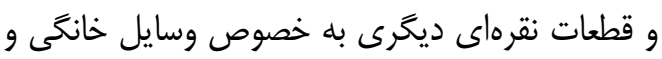

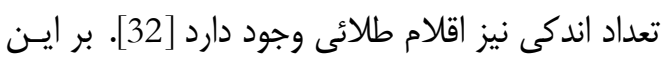

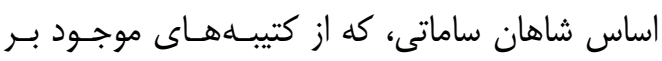

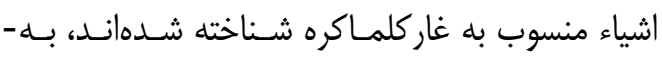

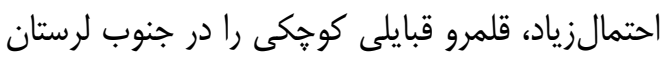

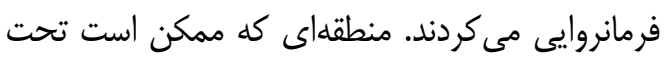

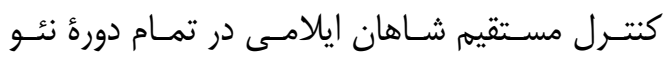

ايلامى بوده باشد [33].

\section{ז- ז. محوطه باستانى كلماكره}

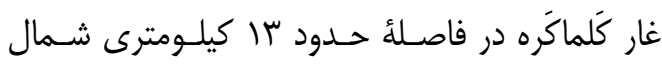

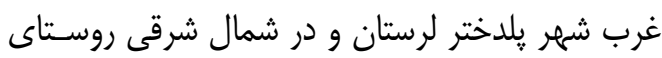

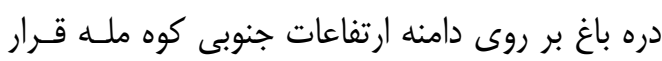

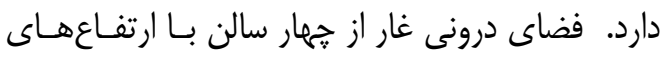

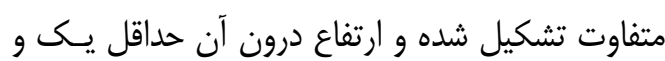

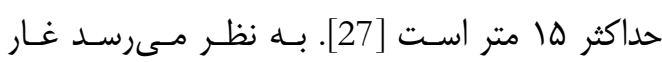

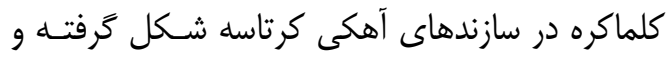

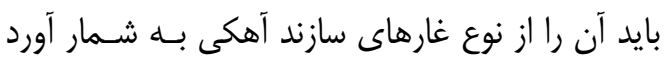

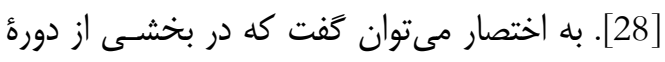
مس و سنَ جديد و حتى عصـر مفـرغ ميانـه، درون

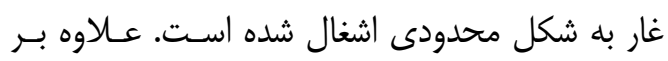

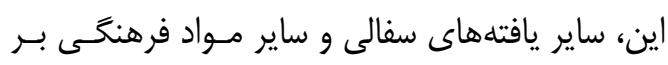

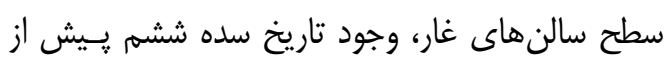

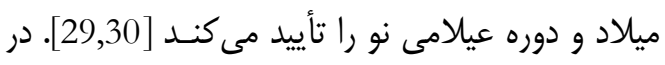

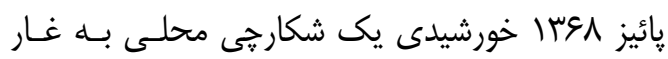

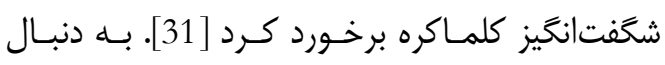

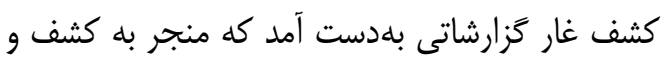

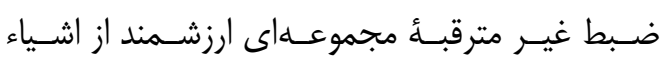

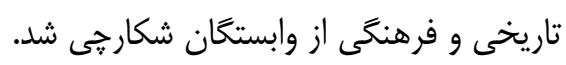
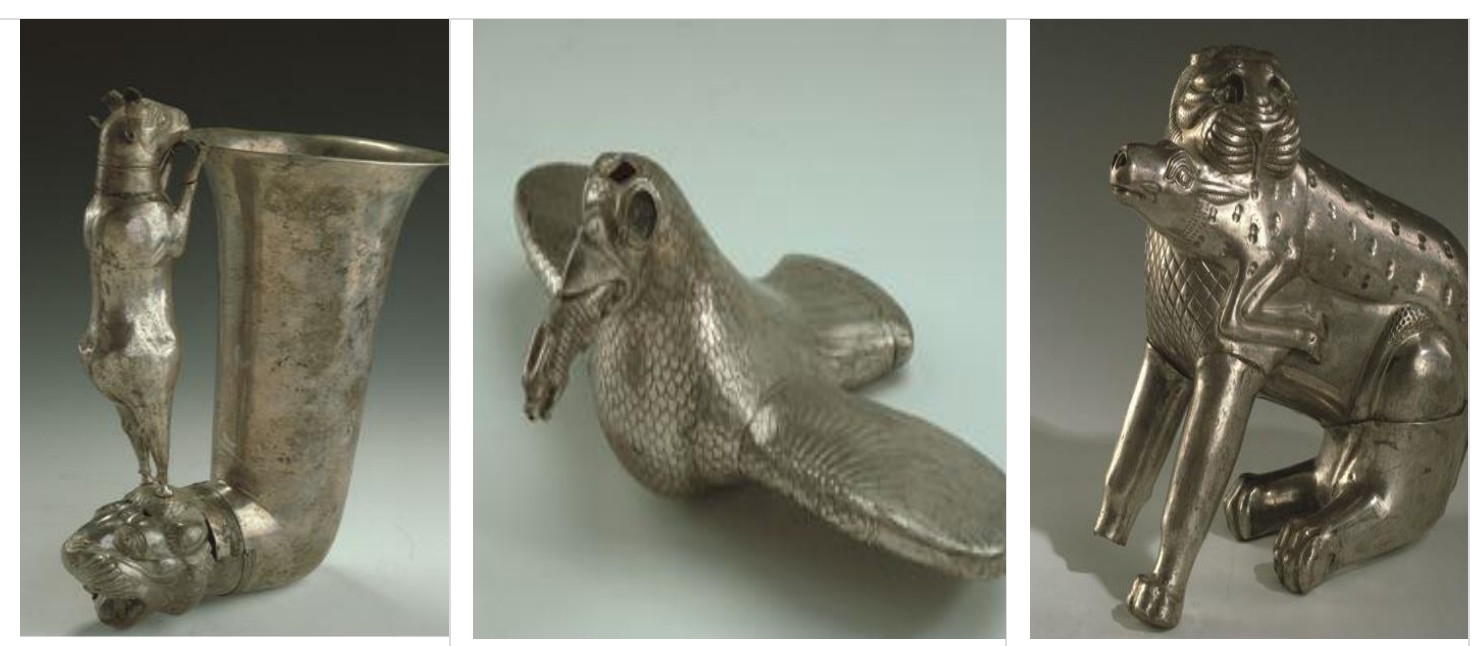

شكل ז: تعدادى از اشياء نقرهاى كلماكره - مجموعه قلعه فلك الافلاك - ميراث فرهنكى لرستان.

Fig. 2: some of silver objects of Kalmakreh - Qala-e-Falak-ol-Aflak Collection - Lorestan Cultural Heritage 

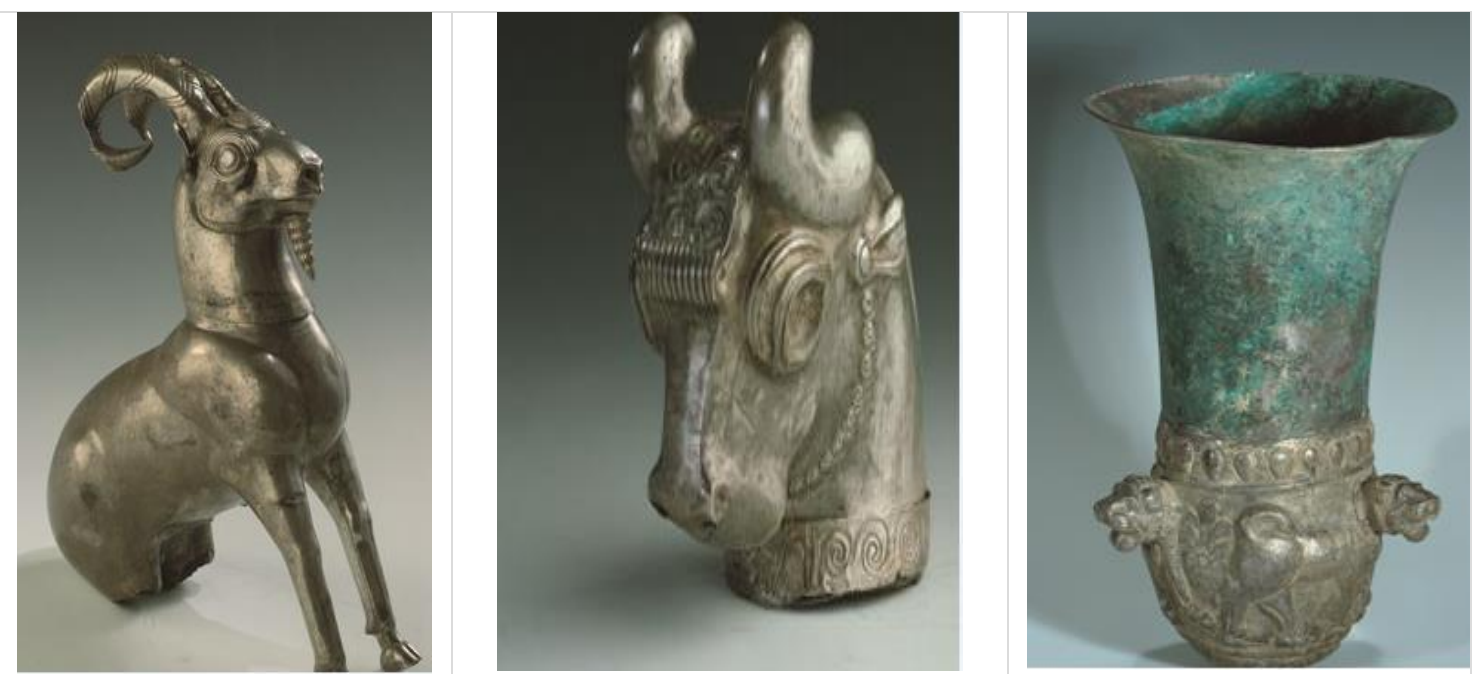

ادامه شكل ז: تعدادى از اشياء نقرهاى كلماكره - مجموعه قلعه فلك الافلاك - ميراث فرهنكى لرستان.

Fig. 2: some of silver objects of Kalmakreh - Qala-e-Falak-ol-Aflak Collection - Lorestan Cultural Heritage

محبوبيان و.... تعداد اشياء اين مجموعه بسيار بيش از

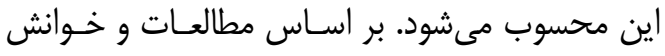

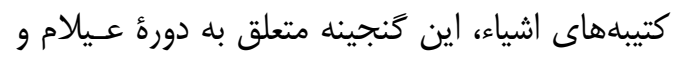
خاندان سمتىها اسـت. درشـكل ك تعـدادى از اشـياء نقرهاى شاخص اين مجموعه ديده مىشود.

\section{" آس. مجموعه جوبتجى}

در سال عربّا شمسى در زمان انجام كارهاى عمرانى

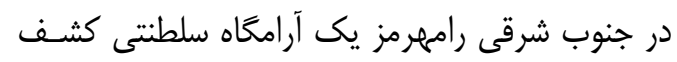

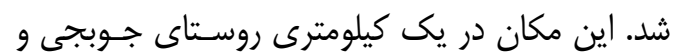

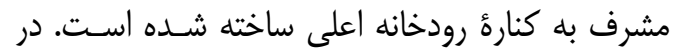
سطح اين محوطه سفالهاى عيلامس، هخامنشى و و ونانه

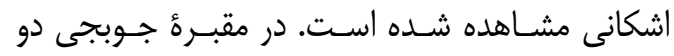
تابوت شبيه به تابوت ارجان همراه با بقاياى جســ دو زن ييدا شده است. در اين مقبره تعـداد زيـادى اشـياء

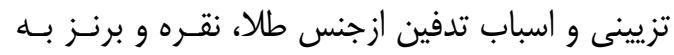

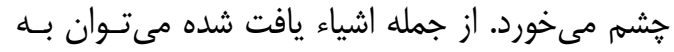

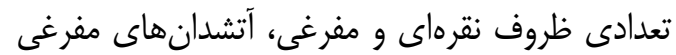

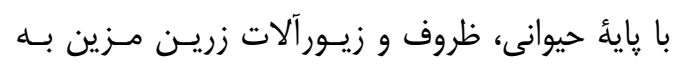

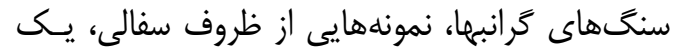

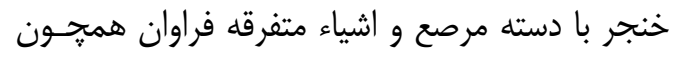
اشياء استخوانى وحتى قيرى وآهنى اشاره كرد [35].
نظارتىزاده در پايان نامـهُ فـوق ليسـانس خـود بــــاى

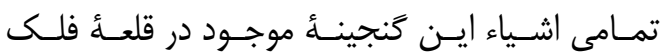

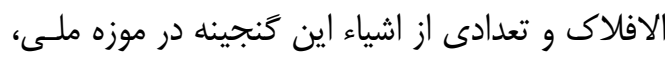

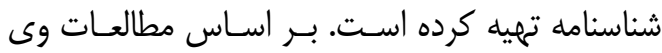

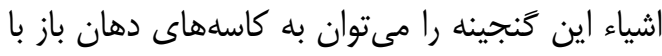
برجستخىهاى لانه زنبـورى، كاسـهـهـاى دهـان بـان بـاز

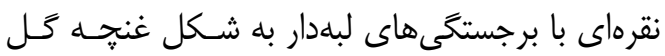

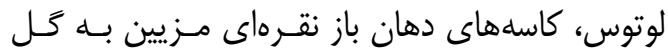

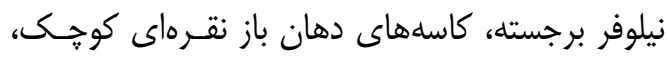

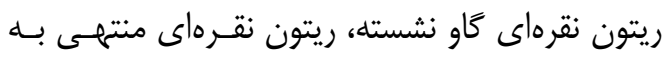

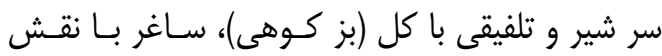

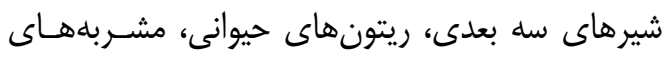
نقرهاى لولهدار مزيّن به سر كاو، دورى يا سينى نقره-

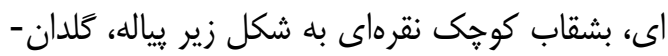

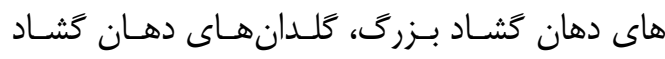

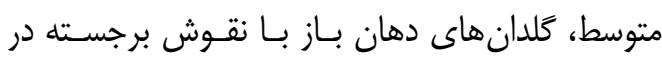

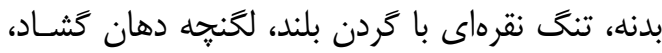

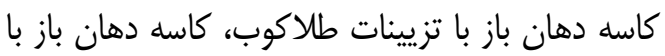

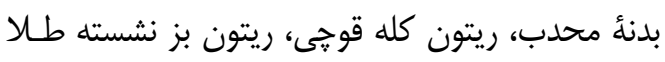

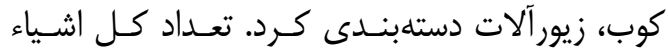

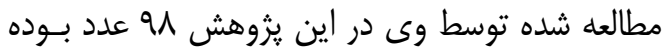

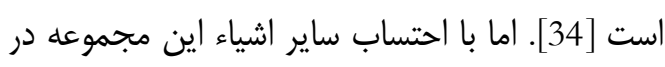

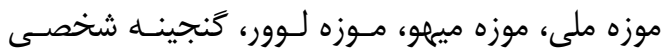


مفرغى يك خنجر آهنين، يك عدد كترى، يك ظرف

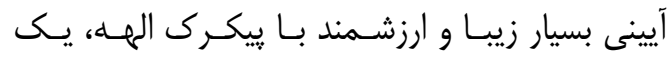

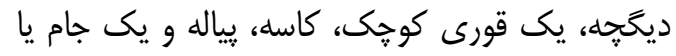

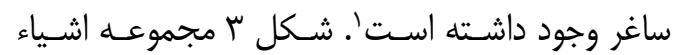
نقرهاى اين گَنجينه را نمايش مى دهد.

\section{إ-س-س.اشياء نقرهاى جوبجى}

آرمان شيشهر دركتاب آرامخَـاه دو بـانوى عيلامسى،

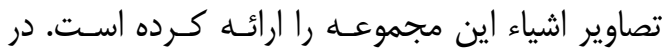
ميان صدها شىء كشف شده در اين گنججينه ارزشمند، تعداد هr شىء نقرهاى وجود داشته است. از اين تعداد

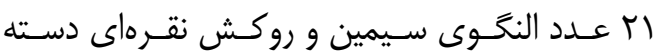

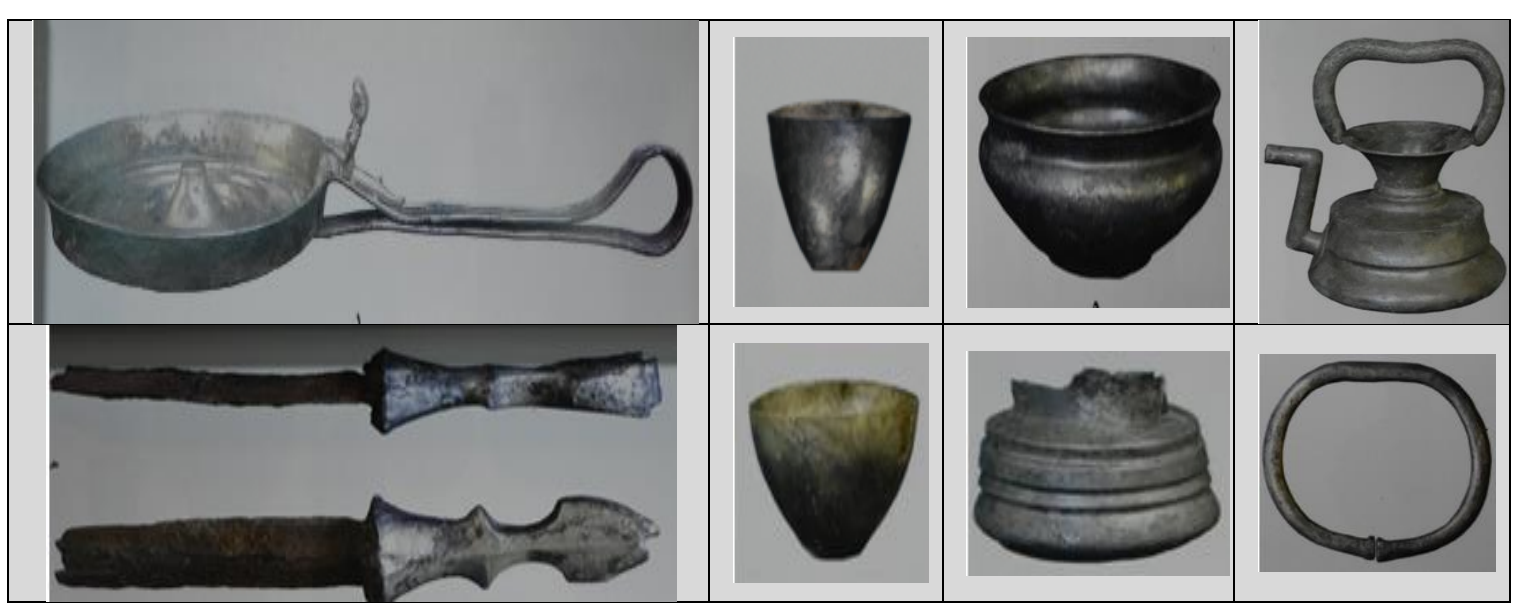

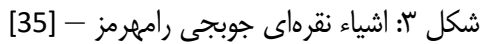

Fig. 3: Jobji Ramhormoz silver objects - [35]

مقايســه داشــته باشــد. فرضــيه دوم اينكــهـ مــدل زئوشيميايى در اين سه منطقه بر اساس شباهتهـاى اشياء مىتواند مدل مشخصى باشد.

\section{ع. مواد و روش ها} 1-ع. مطالعات آزمايشًَاهي

با توجه به تنوع آثار موجود فلزى در اين مجموعـهـهـا

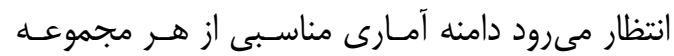

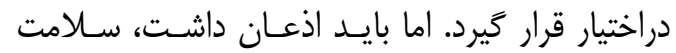

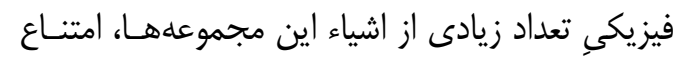

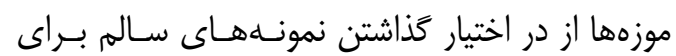

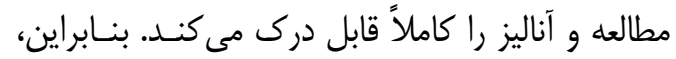
به منظور يبيشبرد مرحلة نمونهبـردارى، از مـوزههــاي مالكِ اين مجموعلها درخواست شد تا از ميان نمونههاى آسيب ديـده كـهـ داراى قطعـات كوجــ قابــل برداشت هستند، نمونههايى را در اختيار اين يروزه قرار دهند. با انتخاب روش XRF يرتابـل بــراى مطالعـات

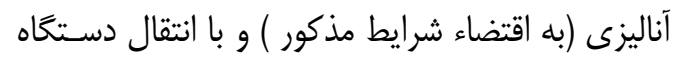

آثـار بــهدسـت آمــده از آرامخَـاه جــوبجى، ارجـان و وكان

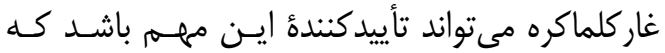
تمدن عيلام در اين برهذه زمانى بسـيار قدرتمنــد و بــا

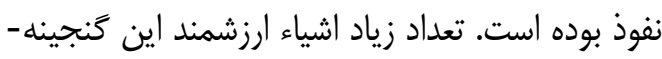
ها باخصوص اشياء فلزى و به ويزه اشـياء فلـزى بــر

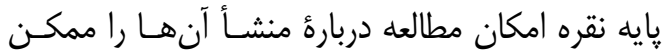
مـى ســازد. وجــود شــباهت و نزديكـى، در سيســتم مشخص زئوشيميايى تشكيل شده در اشياء فلـزى بـر

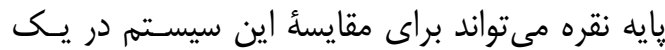

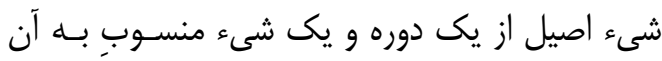
دوره، به عنوان زايگاه دادهها مورد استفاده قرار گيـرد.

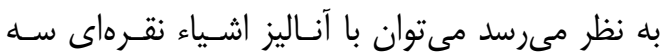
مجموعةٌ مذكور، مدل زئوشيميايى اشياء نقـرهاى دوره عيلام، متعلق به ايران رادر محدودهد دادههاى اين سه مديه منطقه استخراج كرد. در اين بررسى دوفرضيه براى ما متصورّاست: فرضيه اول اينكه تركيب آليـاز اشـياء در اين سه منطقه از نظر عناصر اصلى، جزئسى و عناصـر كمياب مىتواند شباهتهاى قابل دستهبنـدى و قابـل 
مطالعُ آثار باسـتانى فلـز هسـتند [36]. بنــابراين، بــاــا عنايت به توضيحات فوق در مجموع، تعداد سب شـى

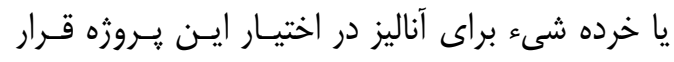
كرفت. در جدول ا اطلاعات اين اشياء ارائه شده است.
به موزهُ مربوطه، ترتيبى اتخاذ شد تا اشياء كوخكى كه

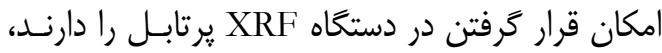

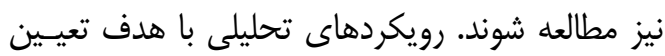

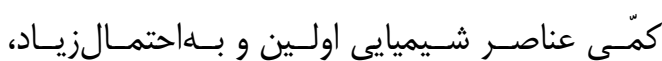

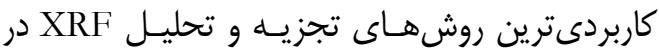

جدول ا: نمونهاى آناليزشده از هر سه كلكسيون

Table 1: analyzed samples from all three collections

\begin{tabular}{|c|c|c|}
\hline $\mathrm{XRF}$ & Collection name & sample \\
\hline$*$ & Kalmakreh - Lorestan & 36 \\
\hline$*$ & Kalmakareh - Lorestan & 39 \\
\hline * & Kalmakareh - Lorestan & 50 \\
\hline$*$ & Kalmakareh - National Museum & $\mathrm{C}$ \\
\hline$*$ & Kalmakareh - National Museum & $\mathrm{D}$ \\
\hline$*$ & Kalmakareh - National Museum & $\mathrm{F}$ \\
\hline * & Kalmakareh - National Museum & M \\
\hline$*$ & Kalmakareh - National Museum & $\mathrm{N}$ \\
\hline$*$ & Kalmakareh - National Museum & $\mathrm{O}$ \\
\hline$*$ & Jobji & 2960 \\
\hline$*$ & Jobji & 2911 \\
\hline * & Jobji & 2918 \\
\hline$*$ & Jobji & 2919 \\
\hline * & Jobji & 2920 \\
\hline$*$ & Jobji & 2921 \\
\hline$*$ & Jobji & 2922 \\
\hline$*$ & Jobji & 2923 \\
\hline$*$ & Jobji & 2924 \\
\hline$*$ & Jobji & 2925 \\
\hline * & Jobji & 2926 \\
\hline * & Jobji & 2936 \\
\hline$*$ & Jobji & 2899 \\
\hline * & Arjan & 2982 \\
\hline
\end{tabular}

حقيقت انتخاب مناسبترين تكنيك براى يــ آنـاليز

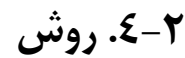
خاص توسط تعدادى از مشخصهها كه مهمتـرين آنها، طبيعت مادهاى كه مى خواهد آنـاليز شـود، انــازئ نمونه موجود، مقدار دقت مورد نياز و تعداد نمونههـاى

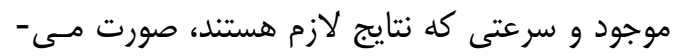

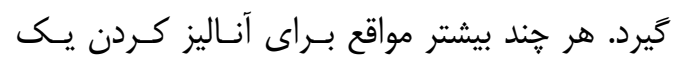
نمونهٔ خاص، اولويتها بايد قبل از اينكه آنـاليز انجـام واقعيتى وجود دارد و آن اين است كه گَاهى نمونسهـ-

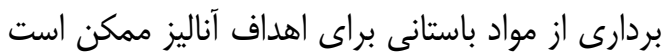

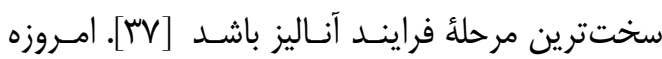

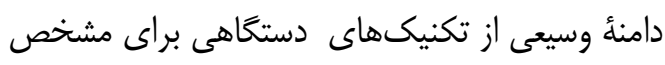

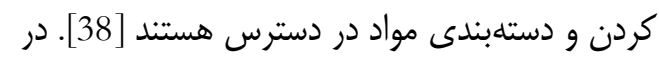


Niton XL3tGOLDD+950

Thermo Scientific كمّى __ نيمه كيفى ارائه شده است.

\section{س-ع. نتايج آناليز نمونهها}

اشياء نقرهاى دنياى باستان اغلب توسط قال كــذارى از

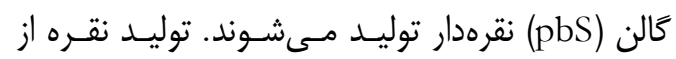

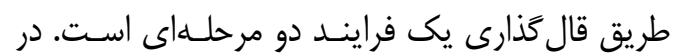
مرحلة اول، كانسنگ نقرهدار تحت شرايط احيايى و با

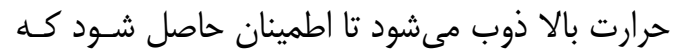
تمام نقرءٔ موجود، احيا و توسط سرب جذب شده است.

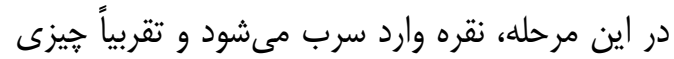

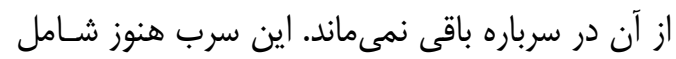

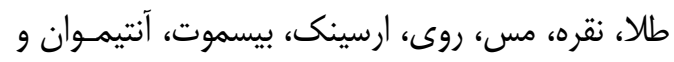
تلوريوم است. مرحلهُ دوم يك اكسيداسيون انتخابى از از

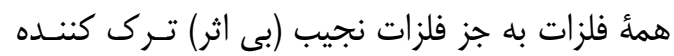

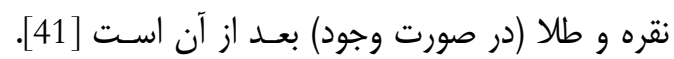
بيشتر ناخالصىها در سربارهاى كه خود هم معمولاً تـا

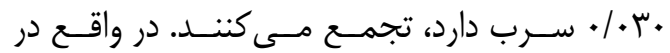

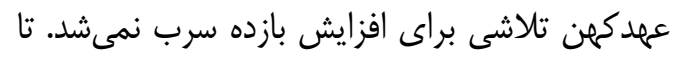

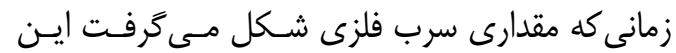

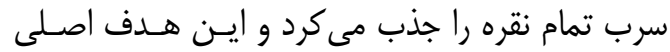

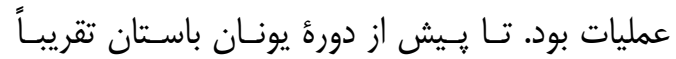

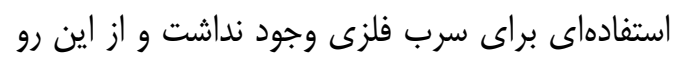
يايين نحَه داشتن بازده سرب به منظور صرفهجويى در

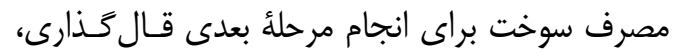

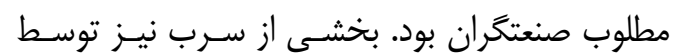

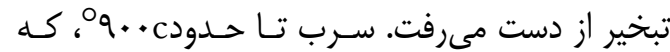

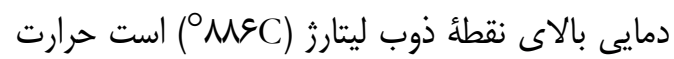

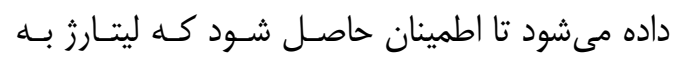

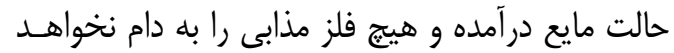

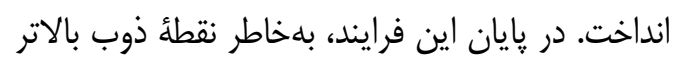

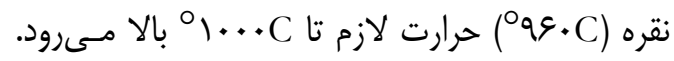

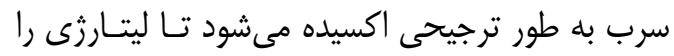

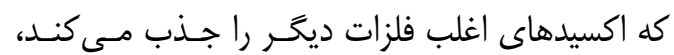
شكل دهد [42].
شود مشخص شوند [39]. روش XRF يك فن بسيار

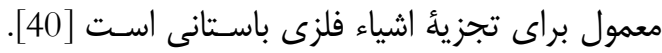

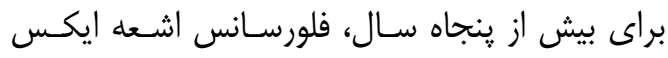

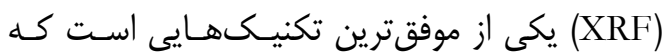

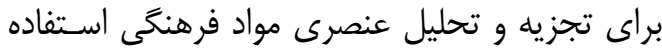

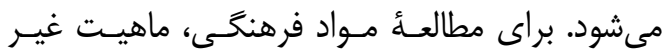

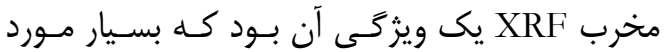

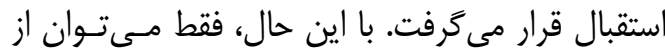

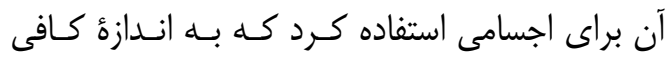

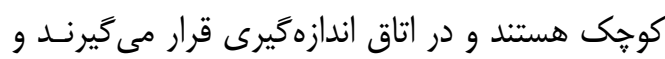

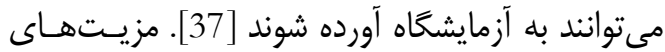

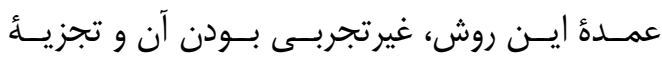

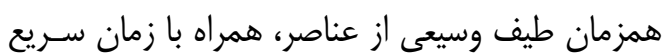

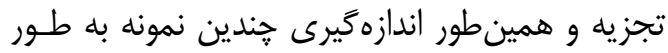

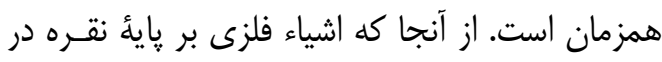

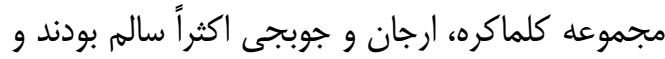
نمونهبردارى از شعء ممكن نبود، تصميم گر فته شد از از روش XRF يرتابل براى انجام آناليزها اسـتفاده شـود.

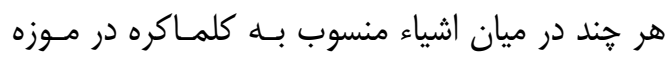

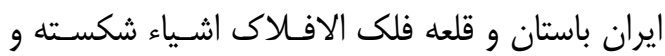

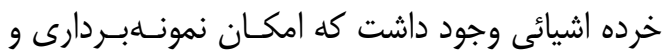

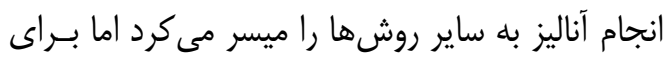

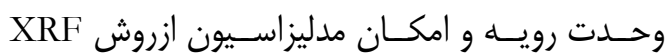
يرتابل استفاده شد. يس از انتخاب تعداد سب نمونه، به

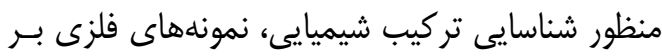

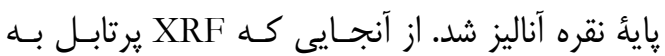

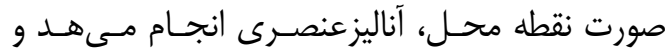

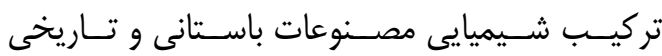

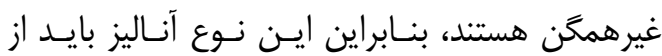
جندين محل كرفته شود و سيس ميـانكَينى از آنهـا

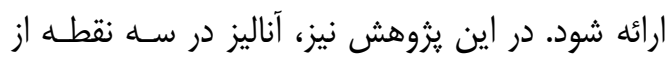

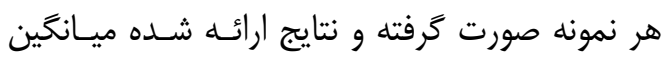

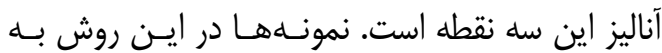

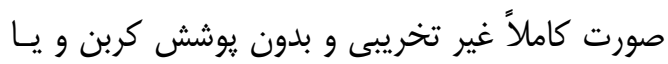

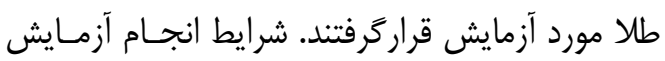
طيفسنجى فلورسانس يرتو ايكس دستى مدل XRF 
جغرافياى معادن يى ببــريم. در حقيقت روشى كـه در

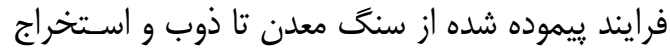

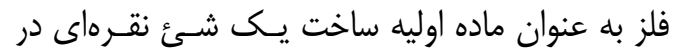
دوران باستان طى مى شده است، موجب مى شده تا در

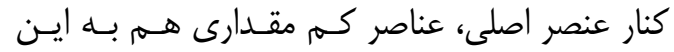

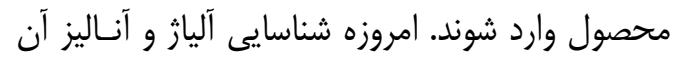

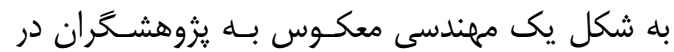
بازشناسى روند مسير طى شده از سنح معدن تا شىى

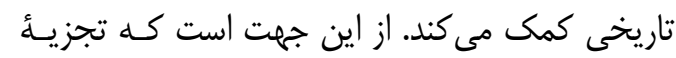

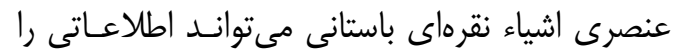

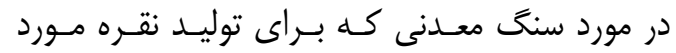

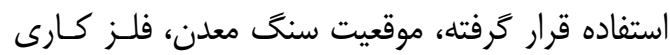

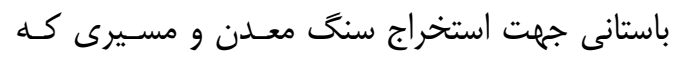
براى تهيئُ اين اشياء طى شده است، به ما بدهد [48]

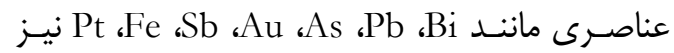

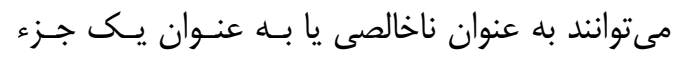

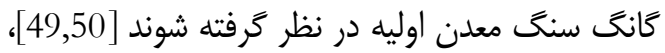

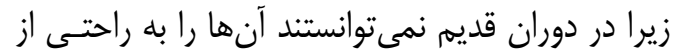

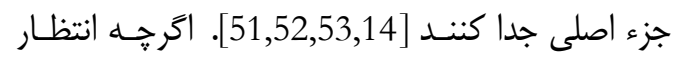
مىرود كه مقدار كمى از اين عناصر در تركيب اشـياء

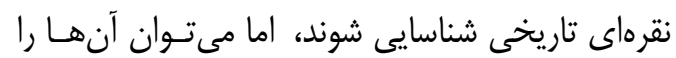

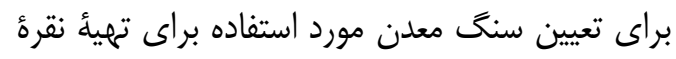

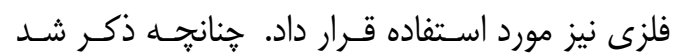
عناصر Pb وb مb مانند ديخر عناصر كمياب، در زمان-

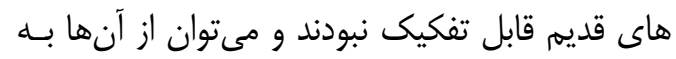

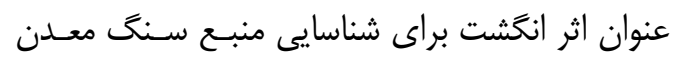

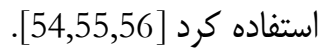
از بين عناصر فقط طلا جزء ناخالصىها نيست و مقدار آن نسبت به نقره در طول قال كذارى و تصفيه و تهيئ

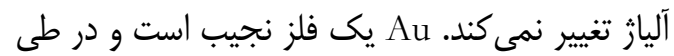

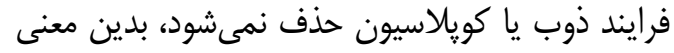

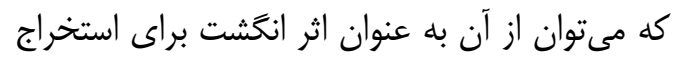

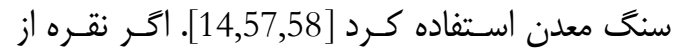

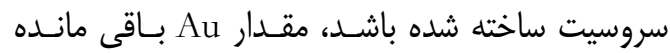

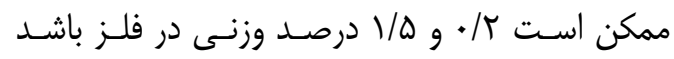

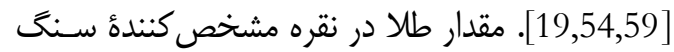

آنتيموان و آرسنيك در مرحلئ اولئُ فرايند قال گـــارى اكسيده و تبخير مى شوند. بنابراين اولين ليتارز شـكل

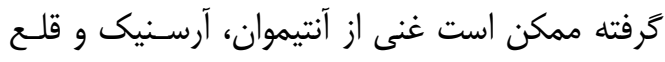
باشد. مس به آهستخى ولى بسيار قبل از بايان قـال كذارى اكسيده مىشود. جداسـازى بيسـموت مشـكل

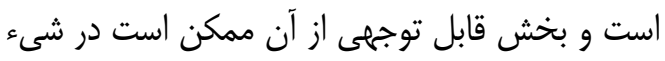

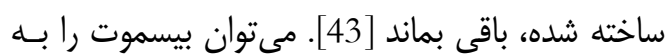

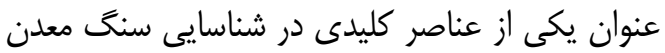

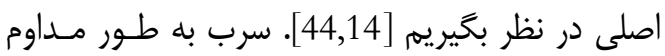

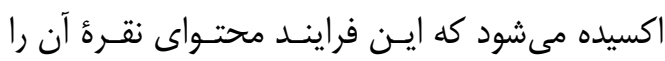

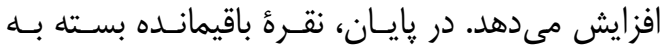

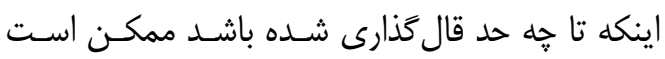

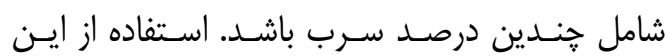
تكنيك براى بلهدست آوردن نقـره در دنيـاى باسـتان

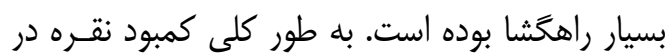
مقايسه با مواد معدنى حاوى نقره، عمدتاً سنگ معلى معدن

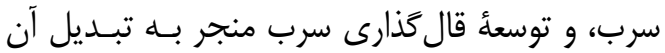

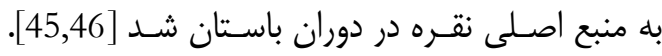

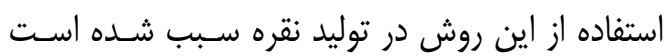

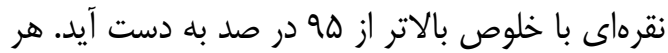

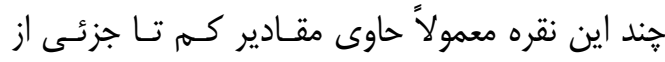

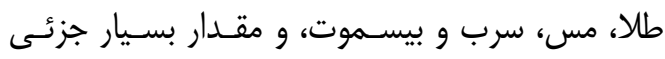

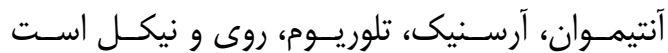
[47,45]. به طور كلى طلا، مس، سـرب و محتويـات

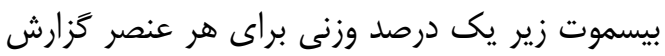

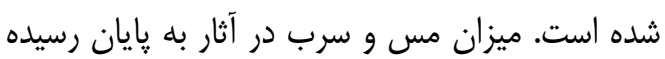
و سكه ها بالاتراست و همجرنين وجود قلع و يـا روى إنى

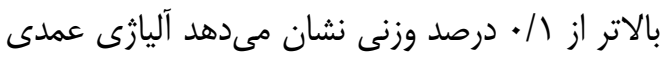

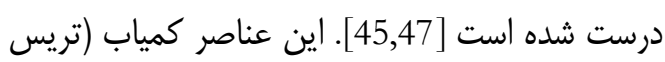

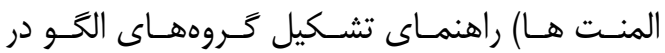
مطالعات زئوشيميايى خواهد بودا در روش استحصال از معادن نقره در قديم بـا معـادن

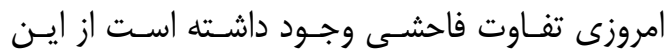

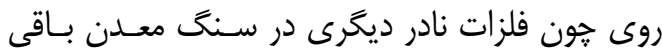

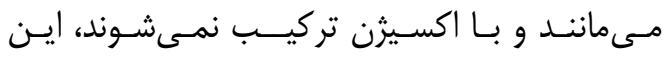

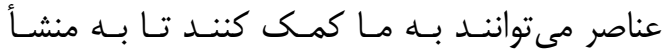


أسانى نيست. مقدار ناخالصى روى و قلع موجود مسى-

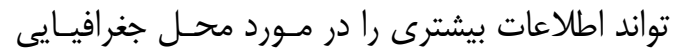

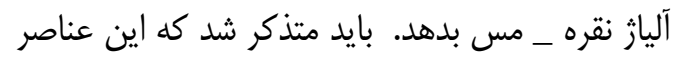

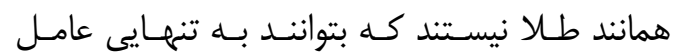
مشخصایى براى دستهبندى اشياء باشد ولى مىتوانند

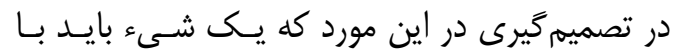

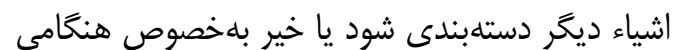
كه مقدار طلاى شىء با اشـياء مـورد مقايسـهـ مشـابه باشد، مؤثر باشند [6,48].
معلنى است كه براى تهيئُ نقره بــهـ كـار رفتـه است.

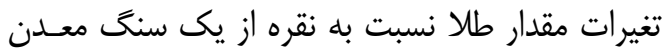

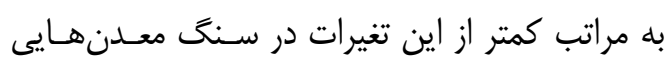

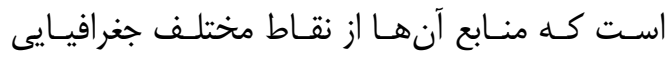

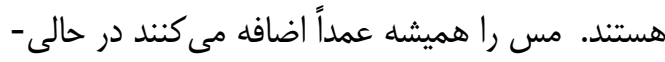

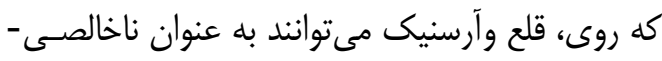

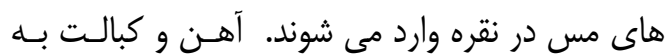
طور ناهمخون در نقره يراكنده هستند [6,48]. به علت

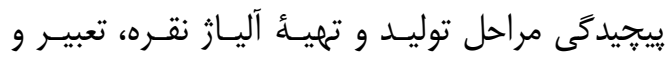

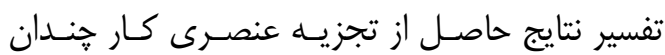

جدول r: نتايج تر كيب شيميايى نمونهاى كلماكره بر حسب درصد وزنى

Table 2: Chemical composition of Kalmakareh samples in W\%

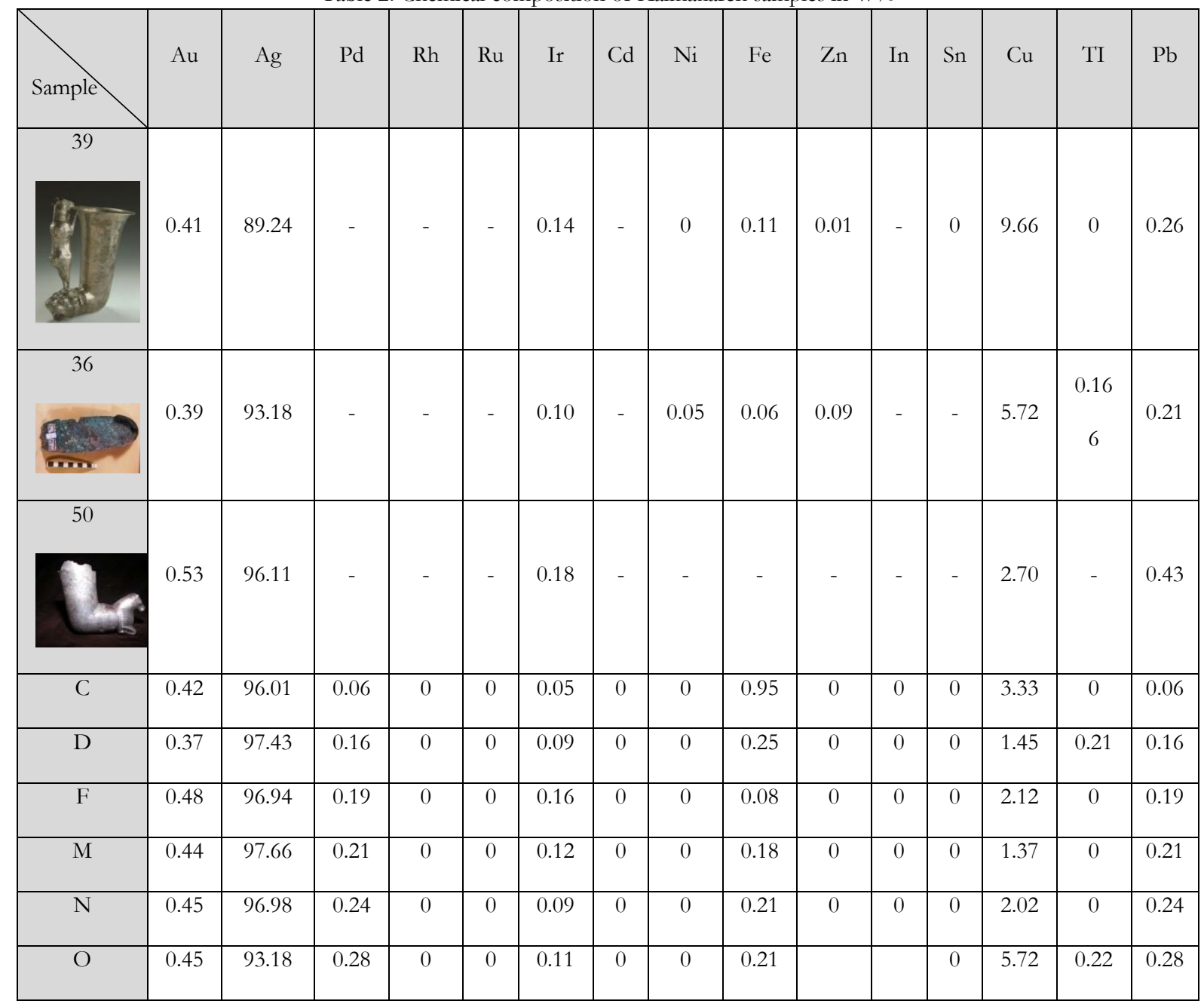


جدول ب: نتايج تركيب شيميايى نمونه ها سى جوبجى بر حسب درصد وزنى :Ch

Table 2: Chemical composition of jobji samples in Wo

\begin{tabular}{|c|c|c|c|c|c|c|c|c|c|c|c|c|c|c|c|}
\hline Sample & $\mathrm{Au}$ & $\mathrm{Ag}$ & $\mathrm{Pd}$ & $\mathrm{Rh}$ & $\mathrm{Ru}$ & Ir & $\mathrm{Cd}$ & $\mathrm{Ni}$ & $\mathrm{Fe}$ & $\mathrm{Zn}$ & In & $\mathrm{Sn}$ & $\mathrm{Cu}$ & TI & $\mathrm{Pb}$ \\
\hline 2926 & 1.16 & 96.57 & 0 & 0 & 0 & 0.44 & 0 & 0 & 0.19 & 0.038 & 0 & 0 & 0.788 & 0.257 & 0.562 \\
\hline 2918 & 0.698 & 95.09 & 0 & 0 & $\overline{0}$ & 0.093 & 0 & 0 & 0.112 & 0.093 & 0 & 0 & 3.34 & 0.507 & 0.036 \\
\hline 2936 & 0.334 & 97.87 & 0.029 & 0.018 & 0.003 & 0.253 & 0.036 & 0 & 0.058 & 0.031 & 0.032 & 0 & 0.371 & 0.426 & 0.206 \\
\hline 2919 & 0.899 & 96.29 & 0.029 & 0.011 & 0.003 & 0.567 & 0.025 & 0 & 0.196 & 0.096 & 0 & 0 & 0.951 & 0.49 & 0.387 \\
\hline 2924 & 0.565 & 94.05 & 0.025 & 0.015 & 0 & 0.086 & 0 & 0 & 0.353 & 0.231 & 0.026 & 0 & 3.89 & 0.679 & 0.045 \\
\hline 2920 & 0.788 & 97.3 & 0.032 & 0.013 & 0.004 & 0.372 & 0.027 & 0 & 0.059 & 0.077 & 0.026 & 0 & 0.35 & 0.615 & 0.328 \\
\hline 2925 & 0.491 & 88.72 & 0.047 & 0.023 & 0.023 & 0.09 & 0.037 & 0 & 0.518 & 0.156 & 0.044 & 0.657 & 8.71 & 0.423 & 0.043 \\
\hline 2923 & 1.75 & 96.39 & 0 & 0 & 0 & 0.305 & 0 & 0 & 0.115 & 0.048 & 0 & 0 & 0.627 & 0.491 & 0.23 \\
\hline 2922 & 0.919 & 96.05 & 0.028 & 0.011 & 0.003 & 0.672 & 0.028 & 0 & 0.076 & 0.069 & 0.024 & 0 & 0.451 & 0.84 & 0.572 \\
\hline 2921 & 0.918 & 97.07 & 0 & 0 & 0 & 0.209 & 0 & 0 & 0.015 & 0 & 0 & 0 & 1.33 & 0 & 0.138 \\
\hline 2899 & 0.138 & 98.33 & 0.045 & 0.014 & 0.004 & 0 & 0.031 & 0 & 0.159 & 0.027 & 0.034 & 0.511 & 7.21 & 0.371 & 0.071 \\
\hline 2911 & 1.45 & 93.04 & 0.019 & 0 & 0 & 0.793 & 0.02 & 0 & 0.185 & 0.074 & 0 & 0 & 1.93 & 0.875 & 1.59 \\
\hline 2960 & 0.552 & 97.06 & 0 & 0 & 0 & 0.089 & 0 & 0 & 0.517 & 0 & 0 & 0 & 1.5 & $0 / 193$ & 0.08 \\
\hline
\end{tabular}

جدول عا: نتايج تركيب شيميايى نمونه ارجان بر حسب درصد وزنى

Table 2: Chemical composition of Argan sample in W\%

\begin{tabular}{|c|c|c|c|c|c|c|c|c|c|c|c|c|c|c|c|}
\hline Sample & $\mathrm{Au}$ & $\mathrm{Ag}$ & $\mathrm{Pd}$ & $\mathrm{Rh}$ & $\mathrm{Ru}$ & $\mathrm{Ir}$ & $\mathrm{Cd}$ & $\mathrm{Ni}$ & $\mathrm{Fe}$ & $\mathrm{Zn}$ & $\mathrm{In}$ & $\mathrm{Sn}$ & $\mathrm{Cu}$ & $\mathrm{TI}$ & $\mathrm{Pb}$ \\
\hline 2982 & & & & & & & & & & & & & & \\
\hline & & & & & & & & & & & & & \\
\hline
\end{tabular}


كرد. اينديوم وكادميوم معمولاًا از كانسار سرب آمدهاند

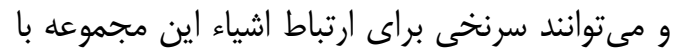
اشياء ديخر در اين دوره باشند. در ترسيم نمودار زئوشيميايى تريس المنتها (عناصـر كمياب ) در نمونههاى جوبجى، ملاحظه مىشود كـه ترنه در جهار نمونه از اشياء مطالعه شده در اين مجموعـاءه،

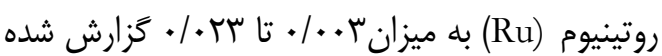

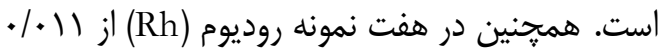

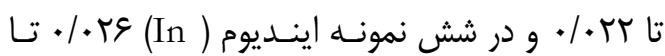
بَاء٪/ درصد وزنى نمونه متغير بـوده اسـت. از ميـان

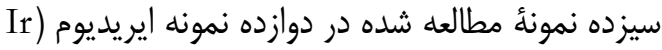

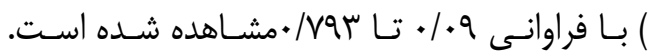

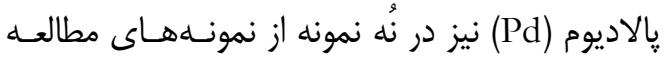

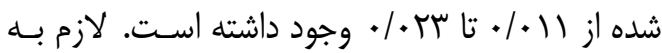
ذكر است عناصر Ir , Pd, Rh, Ru به عنوان عناصـر

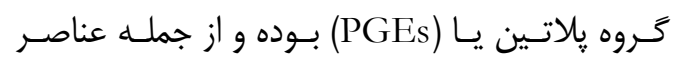

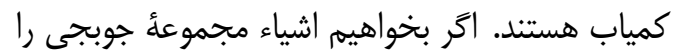
از نظر زئوشيمى عناصر كمياب بررسى كنيه مىتـوان

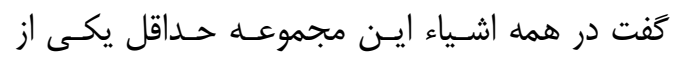
عناصر كمياب كروه پِاتين موجود است.

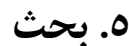

در مجموع، سيزده نمونه اشياء نقرهاى جوبجى تحـت

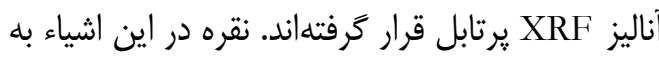

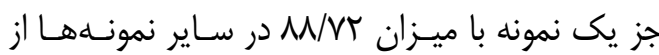
• •

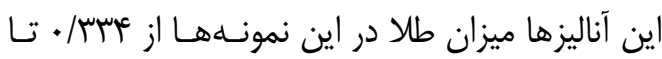

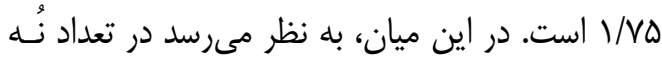

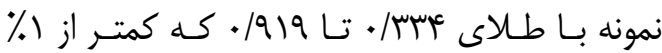
است، طلا از سنگ معلن همراه اثر بـوده اسـت و در

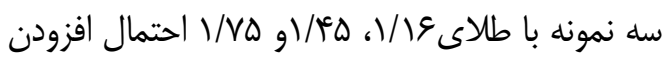

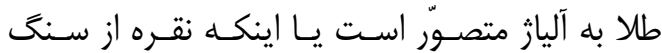
سروسيت استخراج شــه اسـت [19,54,59]. در ايـن

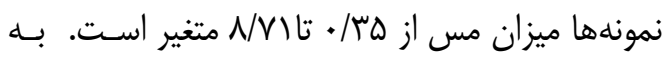

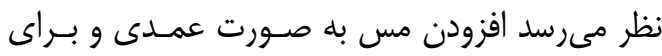

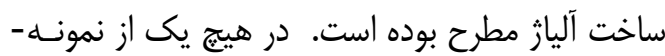

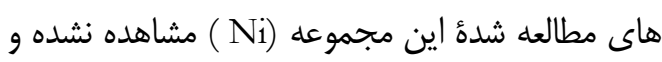

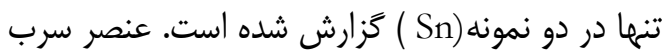

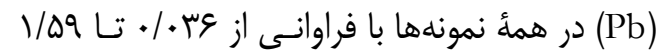

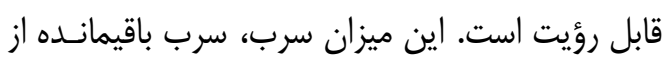

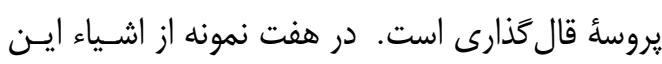
مجموعه مىتوان مقاديرى از كادميوم (Cd ) مشاهده
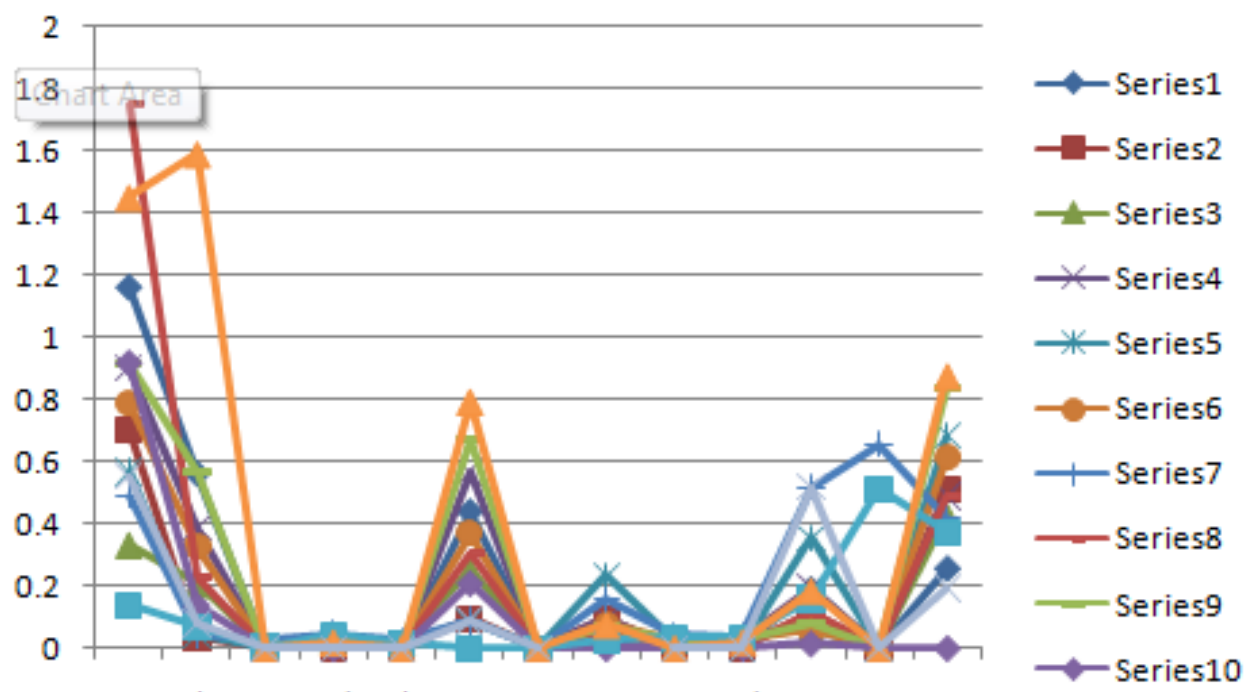

$\mathrm{Au} P \mathrm{~Pb}$ Ru $\mathrm{Pd}$ Rh Ir $\mathrm{Ni} \mathrm{Zn}$ In $\mathrm{Cd} \mathrm{Fe} \quad \mathrm{Sn} \mathrm{Ti}$

شكل عا: نمودار توزيع فراوانى تريس المنتها در نمونههاى جوبجى

Fig. 4: Frequency distribution diagram of trace elements in Jobji samples 
قابل رؤيت است. اين ميزان سرب، سرب باقيمانـــه از

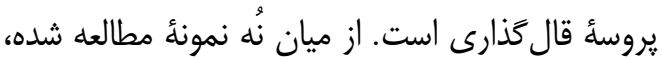

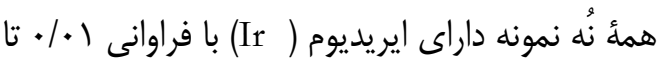

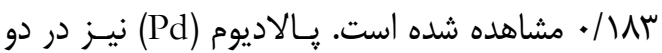

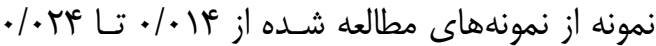

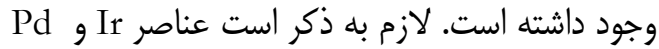

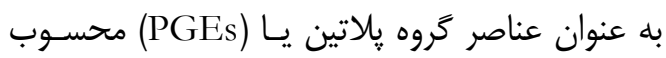

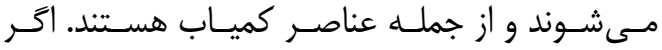

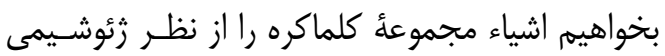

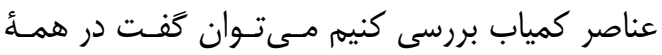
اشياء اين مجموعه حداقل يكى از عناصر كروه يالاتين موجود به نظر مىرسد و اين عنصر در اشـياء مطالعـهـ شده به طور عموم ايريديوم است.
در مجموع نُه نمونسه اشـياء نقـرهاى كلمـاكره تحـت

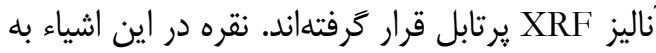

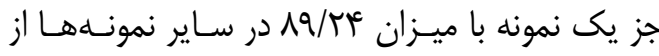

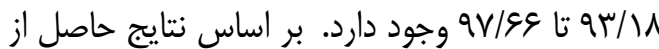
اين آناليزهــا ميـزان طـلا در ايـن نمونـهـهـا از بس/.

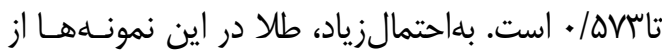

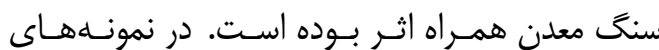

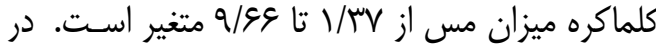

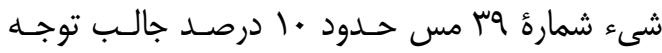

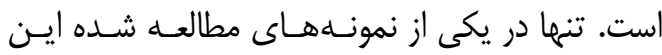

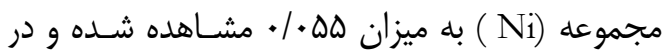

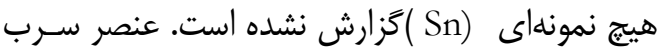
(Pb)

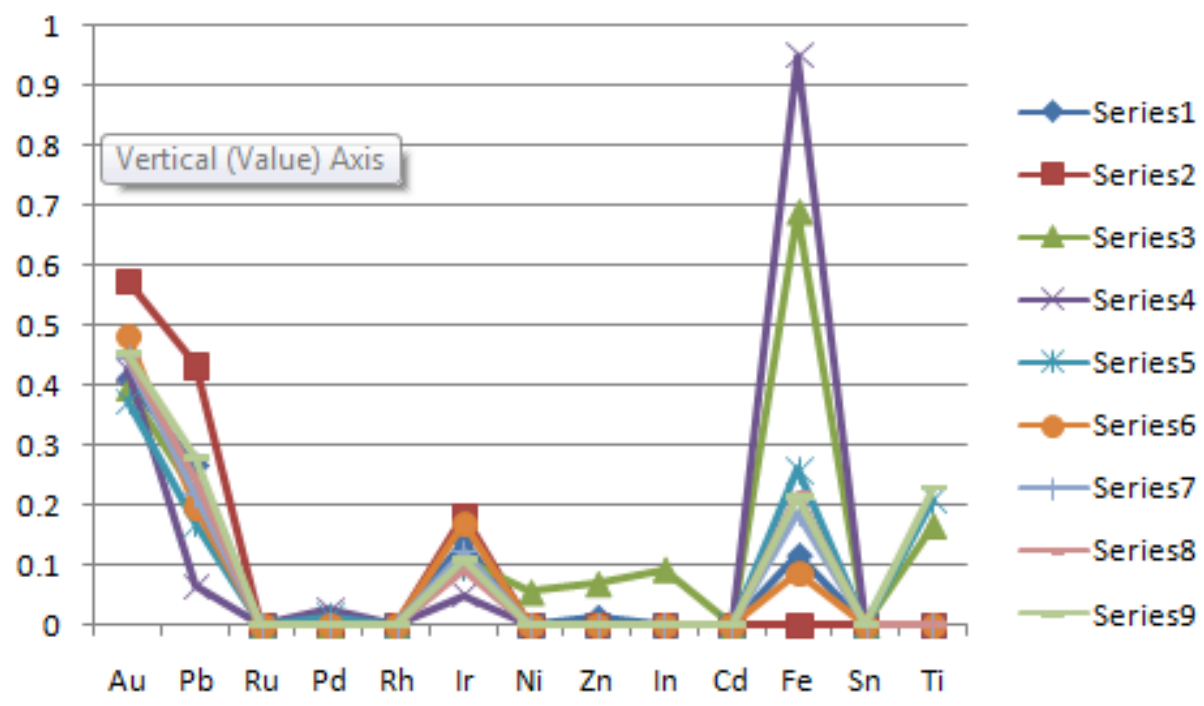

شكل ه: نمودار توزيع فراوانى تريس المنتها در نمونههاى كلماكره

Fig. 5: Frequency distribution diagram of trace elements in Kahmakareh samples

محسوب مى شود. در اين اثر نيز بعضى از عناصر كروه

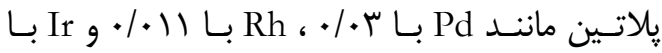

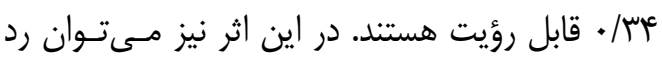

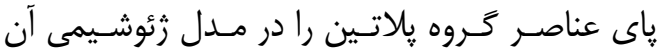

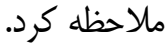

از ميان دو شىء نقرهاى مجموعأه ارجان، تنها امكـان

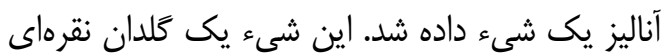

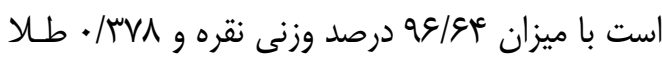

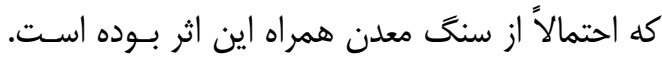

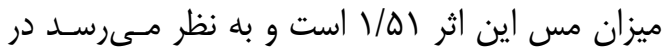

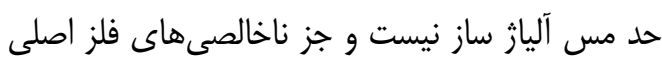




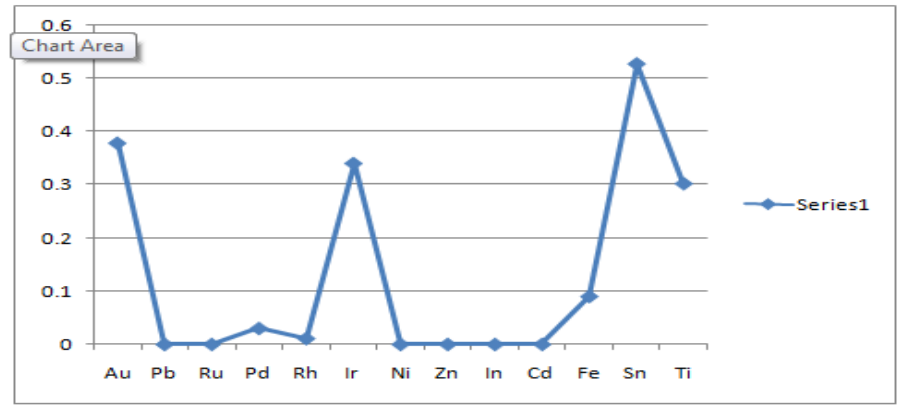

شكل ه: نمودار توزيع فراوانى تريس المنتها در نمونه ارجان

Fig. 4: Frequency distribution diagram of trace elements in Argan sample

شوند و تا حدودى خاصـيت جانشـينى بــا يكـديخر را

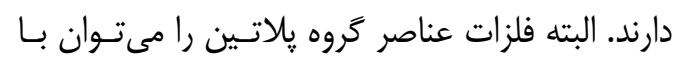

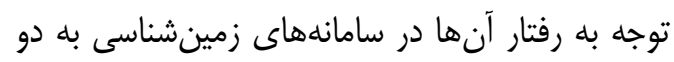

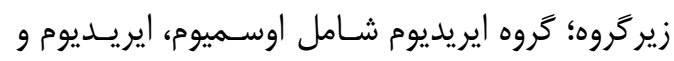

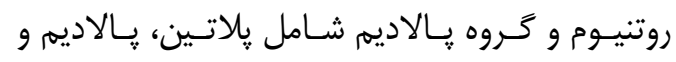

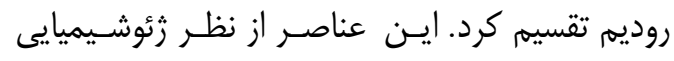

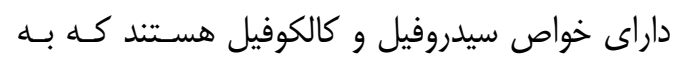

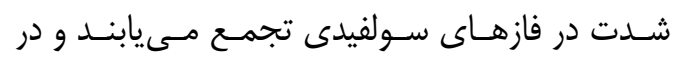

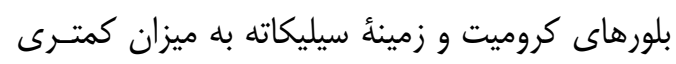

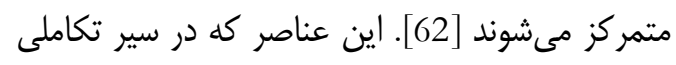

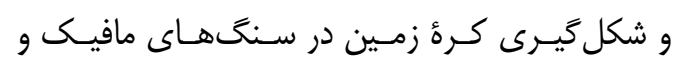

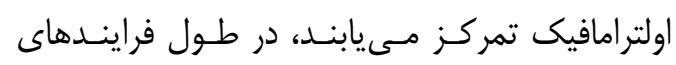

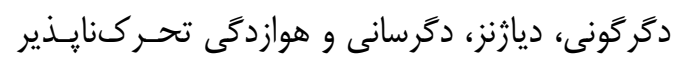

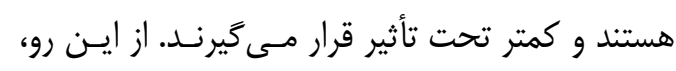

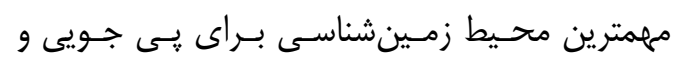

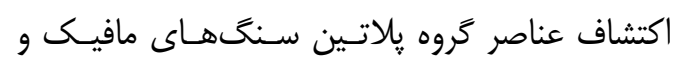

$$
\text { اولترامافيك هستند [63]. }
$$

بررسى دادههاى فوق در رسيدن به ياسخ به دو سئوال

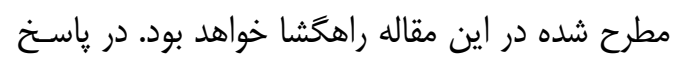
به اين سئوال كه آيا مطالعـأه تركيـب آليـاز و ميـزان

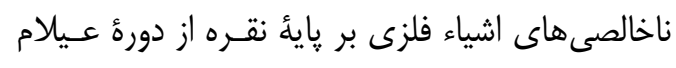

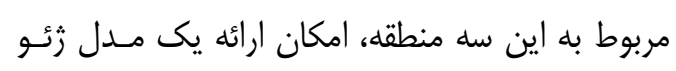

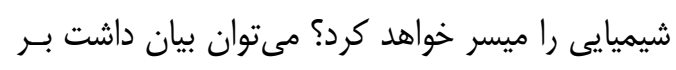

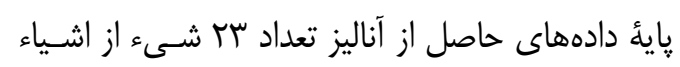

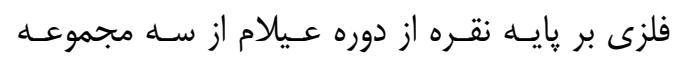

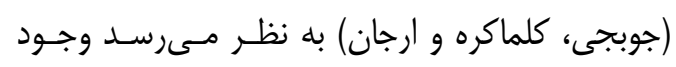

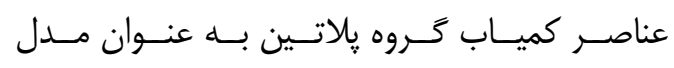
زئوشيميايى اشياء فلزى بر بايه نقره از دوره نئو عيلام بلام
به طور كلى اين نظر وجود دارد كه تجزيـهـ و تحليـل

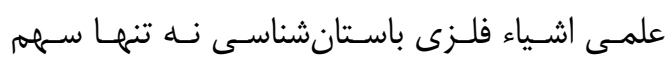

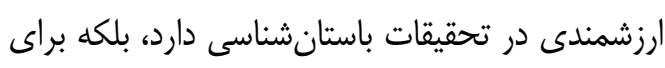

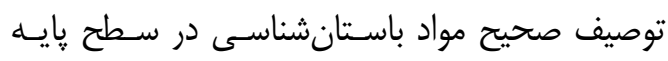

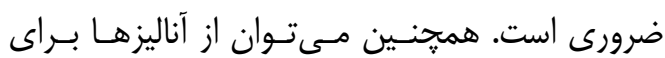

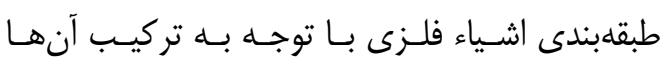

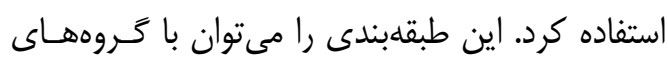
كونهشناسى مقايسه و در صورت همخوانى، مسى كـوان محصولات يك كار كاه خـاص را شناسـايى كـرد [7]ت. سختترين و دشوارترين سئوال مربوط به منشـأ فلـز

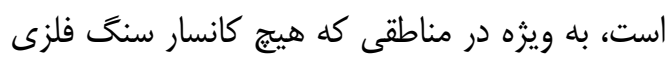
مشخص نيست. ييشنهاد شده است كه فقط مى متوان

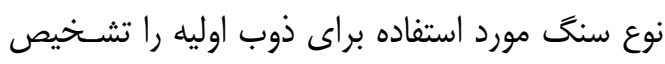

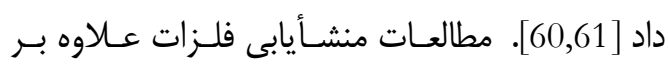

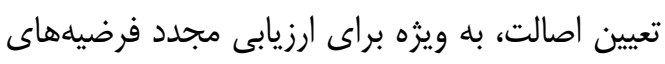

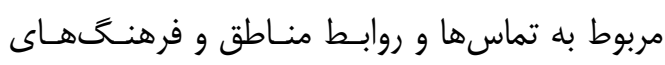
مختلف بر اساس مواد حفـارى شــده و توزيــع آنهـا، مهرم هستند [7].

\section{7. نتيجه كيرى}

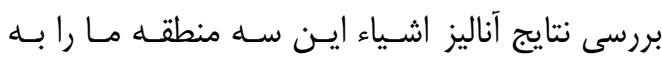

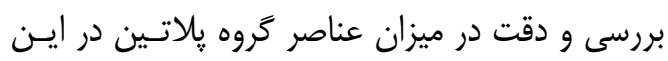

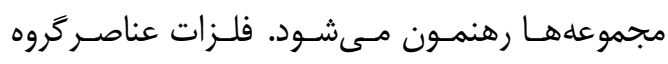

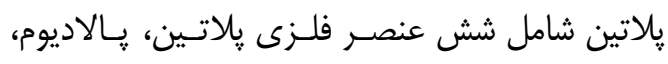

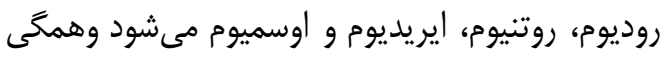

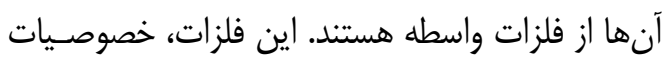

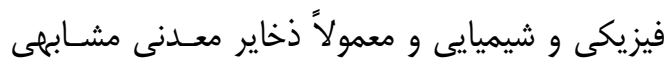

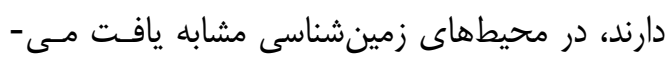


شناسايى و مطالعـات مربوطـهـ را يـك گَـام بـه جلـو

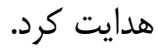

\section{سياسگزارى}

اين مقاله بركرفته از رساله دكترى نويسنده با عنـوان:

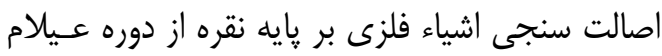

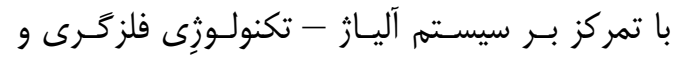
ساخت -ريزساختارها (نمونه مطالعاتى اشياء نقره ايسى

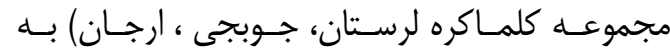

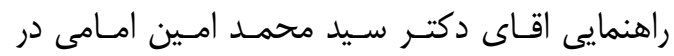

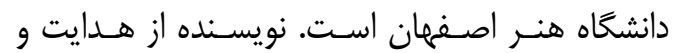
راهنمايى هـاى دكتـر امـامى بسـيار سياسخز اراسـت.

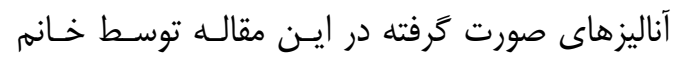

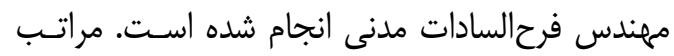
سباس و تشكر خود را از ايشان و آقاى دكتر رحمانى، فران،

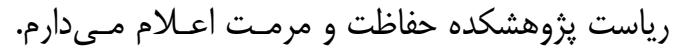
همجنين نويسنده از جناب آقاى نصيرى، امين امـوال

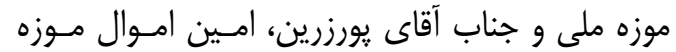

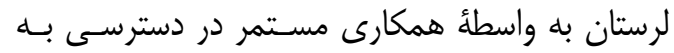
اشياء جوبجى، ارجان و كلماكره سياسخَزارى مىنمايد.

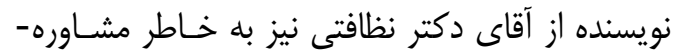
هاى ايشان سياسگزار است.

\section{ي بـ نوشت ها}

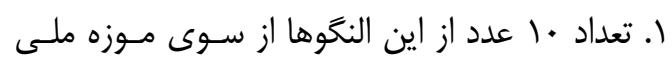

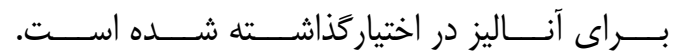

\section{References}

[1] Motamedi N. Activity report of the first season of exploring Kolmakreh cave. Unpublished Lorestan Cultural Heritage Documentation Center.1992. [ in Persian]

[معتمـدى، نصــرت الله. كَز ارش فعاليـت فصـل اول كاوش غار كلماكره. منتشر نشده مركز اسـناد ميـراث

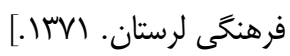

در اين سه مجموعه از ايـران قابـل انتظـار اسـت. در

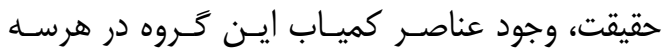
دسته اشياء مطالعه شــده (جوبجى، كلمـاكره و ارجـان) مؤيد اين نكته است كه منشـأ و محـدودود جغرافيـايى سنَ معدن اشياء اين سه مجموعه مىتواند يكسـان

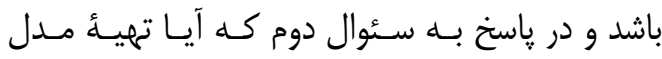

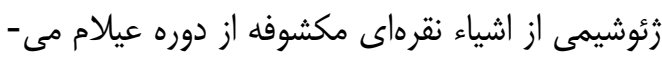

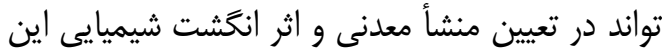

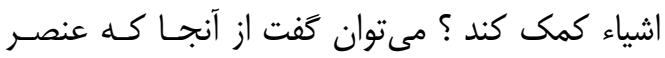

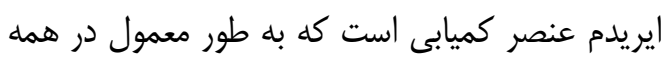

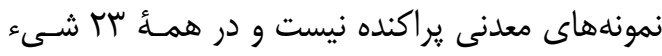

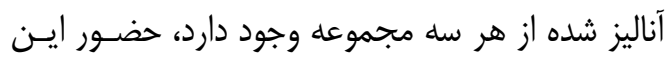

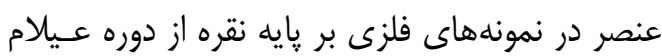

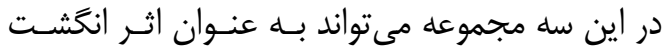
شيميايى اين اشياء معرفى شود.

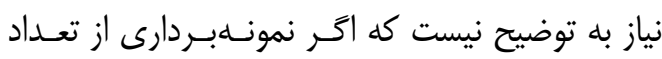
بيشترى از اشياء اين سه مجموعه امكان يذير بود واگر

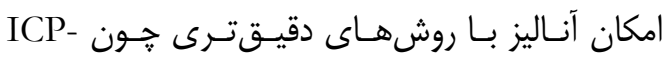

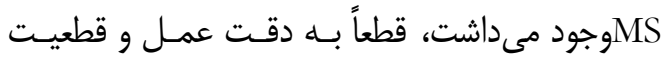

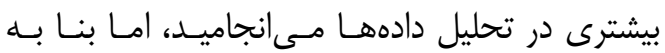
اقتضاى شرايط نمونهبردارى از مجموعـهـهـا وشـــايط

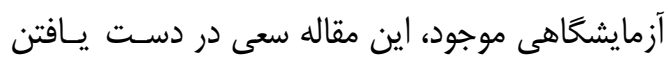

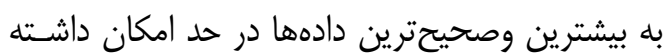

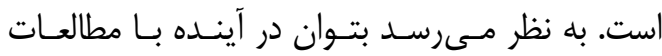

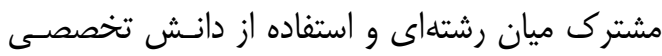

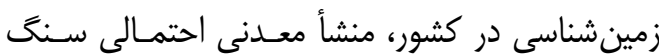

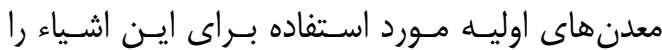

[2] Robbiola L, Blengino JM, Fiaud C. Morphology and mechanisms of formation of natural patinas on archaeological $\mathrm{Cu}-\mathrm{Sn}$ alloys. Corrosion Science. 1998 Dec 1;40(12):2083-111.

[3] Robbiola L, Fiaud C. Corrosion structures of long-term burial $\mathrm{Cu}-\mathrm{Sn}$ alloys: influence of the selective dissolution of copper. Editions de la Revue de Métallurgie. 1993(6):157-62.

[4] Robbiola L, Portier R. A global 
approach to the authentication of ancient bronzes based on the characterization of the alloy-patinaenvironment system. Journal of Cultural Heritage. 2006 Jan 1;7(1):1-2.

[5] Clarke FW. The data of geochemistry. US Government Printing Office; 1920

[6] Rollinson H. Using geochemical data. Evaluation, presentation, interpretation. 1993; 1

[7] Pernicka E. Provenance determination of archaeological metal objects. InArchaeometallurgy in global perspective 2014 (pp. 239-268). Springer, New York, NY.

[8] Helwing B. Silver in the early state societies of Greater Mesopotamia. Metals of Power-Early Gold and Silver. 2014:411-21.

[9] Meyers, P. Z . Major and Trace Elements in Sasanian Silver. Archaeological Chemistry, Advances in Chemistry Series, 138, American Chemical , 22-23.1975.

[10] Smith CS. The interpretation of microstructures of metallic artifacts. InApplication of science in examination of works of art. Proceedings of the seminar: September 7-16, 1965, conducted by the Research Laboratory, Museum of Fine Arts, Boston, Massachusetts 1965 Sep 7 (pp. 20-52).

[11] Gordus AA. Quantitative nondestructive neutron activation analysis of silver in coins.

[12] Cope LH. The metallurgical examination of a debased silver coin of Maximinus Daza issued by Constantine I. Archaeometry. 1973 Jul;15(2):221-8.

[13] Caley ER. Chemical composition of Parthian, coins.

[14] Kallithrakas-Kontos N, Katsanos AA, Touratsoglou J. Trace element analysis of Alexander the Great's silver tetradrachms minted in Macedonia. Nuclear Instruments and Methods in Physics Research Section B: Beam Interactions with Materials and Atoms. 2000 Nov 1;171(3):342-9.

[15] Hughes MJ, Hall JA. X-ray fluorescence analysis of late Roman and Sassanian silver plate. Journal of Archaeological science. 1979 Dec 1;6(4):321-44.
[16] Hajivaliei M, Mohammadifar Y, Ghiyasi K, Jaleh B, Lamehi-Rachti M, Oliaiy P. Application of PIXE to study ancient Iranian silver coins. Nuclear Instruments and Methods in Physics Research Section B: Beam Interactions with Materials and Atoms. 2008 Apr 1;266(8):1578-82.

[17] Khak PM, Kouhpar MK, Hajivaliei M, Khademi F. Elemental Analyses on Ilkhanid period coins by pixe: a case study on King Ghazan Silver coins. Mediterranean Archaeology and Archaeometry. 2013 Jan 1;13(2):83-8.

[18] Nadoshan F, Farahi B, Nayeb M. Recognition of Metal Sources Used for Extracting Silver for Minting Parthian Coins in the Medes Province using the PIXE Method. Archaeological Studies (Faculty of Literature and Humanities, University of Tehran).2011. [ in Persian] ]خادمى ندوشن فرهنَ، نايب يـور محمـد، سـودايى

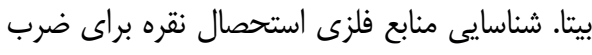

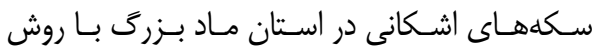

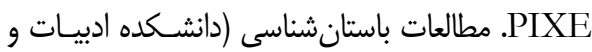

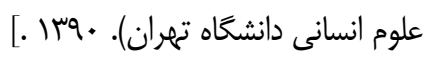

[19] Sodaei B, Hajivaliei M, Khademi Nadooshan F. Possible sources for extraction of silver by comparison of Parthian and Sasanian coins in Mede Satraps. Mediterranean Archaeology and Archaeometry. 2013 Jan 1;13(1):161-70.

[20] Hajivaliei M, Mohammadifar Y, Ghiyasi K, Jaleh B, Lamehi-Rachti M, Oliaiy P. Application of PIXE to study ancient Iranian silver coins. Nuclear Instruments and Methods in Physics Research Section B: Beam Interactions with Materials and Atoms. 2008 Apr 1;266(8):1578-82.

[21] Tohidi F, Khalilian A. Arjan-Behbahan tomb objects review report. Quarterly Asar. 1982: 3( 7, 8, 9). [in Persian]

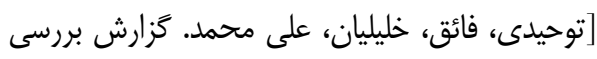

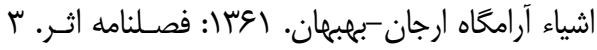

$$
\begin{aligned}
& {[\cdot(9, \wedge, \vee)}
\end{aligned}
$$

[22] Vatandoust A. Restoration, protection and technical study of a number of metal objects in Arjan treasure. Quarterly Asar. 1988(15,16). [in Persian] 
[وطن دوست، رسول، مرمت، حفاظت و مطالعـه فنـى

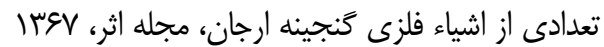

$[.119-V T:(19 g) Q)$

[23] Henkelman WF. The other gods who are: studies in Elamite-Iranian acculturation based on the Persepolis fortification texts. Nederlands Instituut voor het Nabije Oosten; 2008

[24] Potts DT. The archaeology of Elam: formation and transformation of an ancient Iranian state. Cambridge University Press; 2016.

[25] VALLAT F. Kidin-Hutran et l'époque néo-élamite. Akkadica Bruxelles. 1984(37):1-7.

[26] Álvarez-Mon J. Imago Mundi: Cosmological and ideological aspects of the Arjan bowl. Iranica antiqua. 2005 Apr;39(0):203-37.

[27] Ghazanfari, H, Farzin A. Lorestan through history. Cultural Heritage Organization Publications, First Edition, Tehran.1993. [ in Persian]

[غضنفرى، حسين و عليرضا فـرزين. رسـتان در كَذر

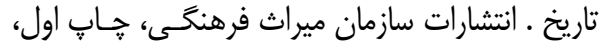

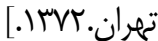

[28] MoradI J. Preliminary Geological Report of Kalmakreh Cave ", Lorestan Cultural Heritage Documentation Center. Unpublished.2007. [in Persian]

[مرادى، جلال.كزارش مقدماتى زمـين شناسـى غـار

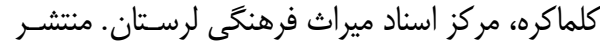

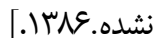

[29] Parviz A. Kolmakreh Cave Registration Proposal, National Registration Number, Cultural Heritage Documentation Center. Unpublished. 2003. [in Persian]

]يرويز، احمد. ييشنهاد ثبت غار كلماكره، شـماره ثبـت .

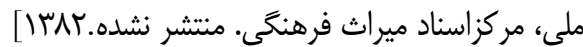

[30] Mosavi M. Identification and survey report of Kalmakreh Poldakhtar Cave in Khorramabad, Lorestan Cultural Heritage Documentation Center. Unpublished. [in Persian]

[موسوى، سيدمحمود. گزارش شناسائى و بررسى غـار

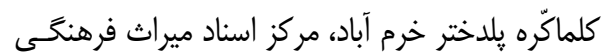

لرستان. منتشر نشده. ع人ץו.]

[31] Ghazanfari H. Kolmakar Cave, Journal of Works: No. 21.1992. [ in Persian]

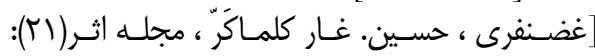

$[.1 m \mathrm{r}$

[32] Keys, David 1994 "to ancient treasure chest", in: The Independent, 1 Feb.1994

[33] Boucharlat R. «Persians, Medes and Elamites, Acculturation in the NeoElamite Period», in: GB Lanfranchi, M. Roaf, R. Rollinger, eds., Continuity of Empire (?) Assyria, Media, Persia. Padova, Sargon Editrice e Libreria, 2003, pp. 181-231. (History of the Ancient Near East/Monographs-V). Abstracta Iranica. Revue bibliographique pour le domaine irano-aryen. 2005 May 15(Volume 26).

[34] Nezarati Zadeh M. Technical and pathological study of silver objects attributed to Kalmakreh Cave, Lorestan, Master Thesis, Tehran University of Arts (Isfahan Campus), unpublished.2009. [ in Persian]

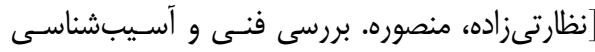

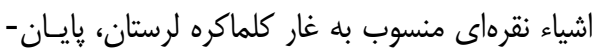

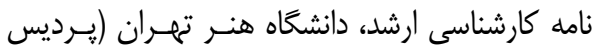

|صفهان)، منتشر نشده.

[35] Shishegar A. Tomb of the Two Elamite Princesses of the House of King ShuturNahunte Son of Indada. Tehran: Cultural Heritage, Handcrafts and Tourism Organization. 2015. [in Persian]

[36] Gigante GE, Ridolfi S, Ricciardi P, Colapietro M. Quantitative analysis of ancient metal artefacts by means of portable energy-dispersive $\mathrm{x}$-ray fluorescence spectrometers: a critical review. Cultural heritage conservation and environmental impact assessment by non-destructive testing and microanalysis. 2004 Aug 15:9-18.

[37] Wilson V. Research methods: sampling. Evidence Based Library and Information Practice. 2016 Mar 4;11(1 (S)):69-71.

[38] Herrmann B. Modern analytical Methods in Art and Archaeology. Chemical Analysis, Series Volume 155.

[39] Goffer, Z . Archaeological Chemistry. Second Edition. Hoboken, New Jersey: . 
Published by John Wiley \& Sons.2007.

[40] Hackens, T. H. X-Ray Fluorescence Spectroscopy Applied to Archaeology, Vol. 1,. PACT Rixensart.1997.

[41] Craddock PT. Early metal mining and production. 1995 May.

[42] Hezarkhani, Z. M.-t.. Archaeometallurgical Researches in Central

Iran.ARCHäologischeMitteilungenaus Iran und Turan.2005.

[43] Pernicka E, Bachmann HG. Archäometallurgische Untersuchungen zur antiken Silbergewinnung in Laurion. na; 1983.

[44] Pernicka E, Eibner C, Öztunalı O, Wagner GA. Early Bronze Age metallurgy in the north-east Aegean. InTroia and the Troad 2003 (pp. 143172). Springer, Berlin, Heidelberg.

[45] Gale NH, Stos-Gale ZA. Ancient Egyptian Silver. The Journal of Egyptian Archaeology. 1981 Aug;67(1):103-15.

[46] Gowland W. VI. - Silver in Roman and Earlier Times: I. Pre-historic and Protohistoric Times. Archaeologia. 1920; 69:121-60.

[47] McKerrell, H. a. Some analyses of Anglo-Saxon and associated Oriental silver coinage. In (. E.T. Hall and D.M. Metcalf, Methods of Chemical and Metallurgical Investigation of Ancient Coinage (pp. 195-209). London, U.K: Royal Numismatic iSociety.1972.

[48] Rahimi F. Lead isotopic detection in silverware of Qoli Qaleh Cave, Proceedings of the Sixth Conference on the Preservation and Restoration of Historical-Cultural Monuments.2003. [ in Persian]

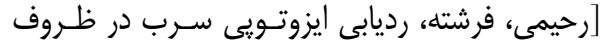

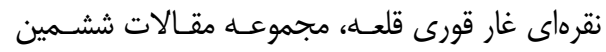

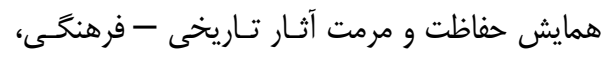

$$
\begin{aligned}
& \text { [.ITNT }
\end{aligned}
$$

[49] [49] Guerra MF, Radtke M, Reiche I, Riesemeier H, Strub E. Analysis of trace elements in gold alloys by SR-XRF at high energy at the BAMline. Nuclear Instruments and Methods in Physics Research Section B: Beam Interactions with Materials and Atoms. 2008 May 1;266(10):2334-8.
[50] Guerra MF. Elemental analysis of coins and glasses. Applied radiation and isotopes. 1995 Jun 1;46(6-7):583-8.

[51] Wanhill RJ. Embrittlement of ancient silver. Journal of failure analysis and prevention. 2005 Feb;5(1):41-54.

[52] Vasilescu A, Constantinescu B, Stan D, Radtke M, Reinholz U, Buzanich G, Ceccato D. Studies on ancient silver metallurgy using SR XRF and microPIXE. Radiation physics and chemistry. 2015 Dec 1; 117:26-34.

[53] Guerra MF. Analysis of archaeological metals. The place of XRF and PIXE in the determination of technology and provenance. X-Ray Spectrometry: An International Journal. 1998 Mar;27(2):73-80.

[54] Meyers P. Production of silver in antiquity: ore types identified based upon elemental compositions of ancient silver artifacts. InPatterns and process: A festschrift in honor of Dr. Edward V. Sayre 2003 (pp. 271-288).

[55] Bacharach JL, Gordus AA. The purity of Sasanian silver coins: an introduction. Journal of the American oriental society. 1972 Apr 1:280-3.

[56] Aydin M. Authenticity of Roman imperial age silver coins using nondestructive archaeometric techniques.

[57] Grün R, Stringer CB. Electron spin resonance dating and the evolution of modern humans. Archaeometry. 1991 Aug;33(2):153-99.

[58] Constantinescu B, Bugoi R, OberlanderTarnoveanu E, Parvan K. Some considerations on X-ray fluorescence use in museum measurements-the case of Medieval silver coins. Romanian Reports in Physics. 2005 Jul 1;57(4):1021.

[59] Sodaei B, Masjedi Khak P, Khazaie M. A study of Sasanian silver coins employing the XRF technique. Interdisciplinaria archaeological Natural Sciences in Archaeology. 2013;4(2):2115.

[60] Friedman AM, Conway M, Kastner M, Milsted J, Metta D, Fields PR, Olsen E. Copper artifacts: correlation with source types of copper ores. Science. 1966 Jun 10;152(3728):1504-6. 
[61] [61] Budd P, Gale D, Pollard AM, Thomas RG, Williams PA. The early development of metallurgy in the British Isles. Antiquity. 1992 Sep;66(252):67786.

[62] Proenza J., Gervilla F., Melgarejo J. C., Bodinier J.-L,Al-rich and Cr-rich chromitites

from the ayari- Baracoa ophiolitic belt (Eastern Cuba) as the consequence of interaction

between volatile-rich melts and peridotites in suprasubduction mantle. Econ. Geol. v. 94.1994.

[63] Bazamad, Marziyeh*, Mirnrjad, Hassan,Rostami, AliandAminzadeh
Mahrokh. Geochemistryand evaluating the abundance of platinum, palladiumand Gold elementsin chromite minerals of pyroxenitesfrom DarvazehChenar in Neyriz area. Fifth Iranian Economic Geology Conference. 11 and 12 September 2013. [ in Persian]

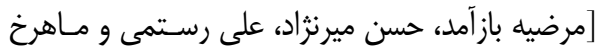

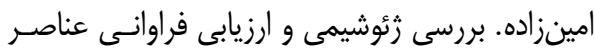

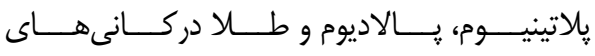

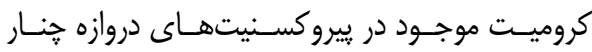

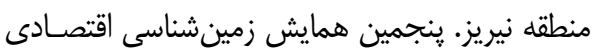

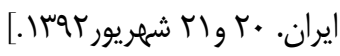

